\title{
La resistencia política como derecho fundamental. Reflexiones a propósito de los cien años de la Constitución mexicana*
}

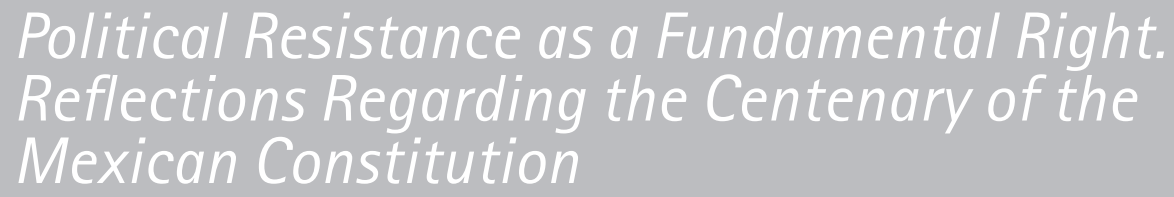

Luis Alberto Pérez Llody**

\section{RESUMEN}

La resistencia politica constituye un fenómeno central en la caracterización de la historia de la civilización. Sus diversas implicaciones están presentes de forma casi ininterrumpida en sus decursos históricos hasta nuestros dias. Sin embargo, no ha sido suficiente la atención teórica que desde las ciencias de la politica y el derecho ha merecido.

Este estudio pretende ofrecer una contribución al actual debate de ideas en torno al centenario de la Constitución mexicana de 1917 mediante una sistematización de los elementos que permiten conceptualizar y proponer al derecho de resistencia como un derecho fundamental. Esta cuestión, sin embargo, no es asumida en la Carta Magna debido a condicionamientos de diversa indole.

PALABRAS CLAVE: Constitución, resistencia politica, derecho de resistencia.

\begin{abstract}
Political resistance constitutes a central phenomenon in the characterization of the history of civilization. Its several implications are present, almost without interruption, in its historical courses to the present days. Nevertheless, theoretical attention that from the sciences of Politics and Low has deserved has not been enough.

This study tries to offer a contribution to the current debate about the centenary of the Mexican Constitution of 1917 through a systematization of elements that allow conceptualizing and proposing the right of resistance as a fundamental right, question that, nevertheless, is not included in the Magna Carta due to conditionings of diverse nature.
\end{abstract}

KEY WORDS: Constitution, political resistance, right of resistance.

\footnotetext{
*Artículo recibido el 25 de febrero de 2016 y aceptado para su publicación el 14 de abril de 2016 .

**Profesor titular de Historia del Derecho en la Facultad de Derecho de la Universidad de Oriente, Cuba. (pllody@gmail.com).
} 


\section{SUMARIO}

1. Prolegómenos

2. La integración conceptual del derecho de resistencia en el pensamiento liberal positivo

3. La resistencia constitucional en México

4. El derecho de resistencia es una cualidad extrajuridica

5. La deconstrucción normativa del derecho a la revolución como lógica del Estado de derecho

6. La revolución como fuente de derecho y el derecho de la revolución

7. Conclusiones

\section{Prolegómenos}

Para la historia americana, y particularmente para su historia constitucional, la celebración del centenario de la Constitución mexicana de 1917 establece una convocatoria a honrar lo que ha significado un hito en la evolución del constitucionalismo moderno. Resultado de un proceso revolucionario de elocuente magnitud, el constitucionalista mexicano colocó el reconocimiento de los derechos al frente del fundamento de legitimidad de todo el sistema político y jurídico de la nación. Ello le otorgó una singular centralidad a la cuestión social y por tanto, se convirtió en paradigma de una época que aún no se agota.

Es así que este estudio pretende ser una contribución al fecundo debate sobre la historia y vigencia de la Constitución mexicana en su centenario y, en general, al necesario balance sobre su presencia en el discurso constitucional de nuestro tiempo. Pero además, en lo particular, ser útil a los estudios sobre los derechos y dentro de estos, al derecho de resistencia implícito y equivalente al principio de salvaguarda constitucional.

En ese camino se hace preciso alcanzar, primero, una base histórica conceptual a partir de la cual poder entender con mayor agudeza por qué es la resistencia un contenido que transversaliza la vocación que, sobre los valores 44 y la justicia, la máxima norma expresa. Conceptualizar un fenómeno de la vida social en el ámbito de las ciencias jurídicas, sin embargo, presupone un desafío. Si adicionalmente se involucra la historia como núcleo de múltiples disciplinas a las que interesa el mismo, estaríamos en condiciones de anunciar un estudio de muy sensible complejidad y provecho.

En el surgimiento mismo de la limitación de las libertades de algunos sujetos históricos por otros que ejercen su dominio sobre el resto de la comunidad se ubica la génesis de esta cuestión: es la resistencia política un concepto de riquísimos abordajes y merecida revalorización. 
La resistencia a la opresión se ha manifestado de diversas maneras. Ambas, opresión y resistencia, están presentes biunívoca y antagónicamente desde el surgimiento de las primeras civilizaciones y pro-formas del Estado-nación. Interesando al derecho, son varias las expresiones que se derivan de la actitud resistente en el universo social. Debemos, sin embargo, concretar en el derecho de resistencia el mayor interés dado el carácter normativo adquirido en su largo tracto histórico hasta nuestros días, lo cual ha guardado, al mismo tiempo, una estrecha relación con la revolución de la que es hija la Constitución mexicana de 1917.

Las revoluciones constituyen un fenómeno imprescindible en la caracterización de la historia moderna, y sus contenidos se han implicado de forma decisiva con el factor de la evolución histórica. Sus consecuencias se evidencian desde fines del siglo XVIII para las Trece Colonias y Francia, hasta los ejemplos aportados por el xx. Tal apreciación ha sido sometida a estudios de diversa indole; sin embargo, no todos han sido capaces de explicar de forma ordenada la relación que se implica en sus decursos con la ciencia jurídica. Esto pasa por reconocer que, debido a la complejidad de sus aristas vistas desde distintas pautas teóricas, no existe un tratamiento unívoco que haga posible la ponderación definitiva de su utilidad en la configuración jurídica del Estado.

En la gradual juridificación de los elementos conceptuales de la revolución se hace imprescindible acudir a la impronta del siglo XIX como resultado de la acumulación histórica. Ello es posible sostenerlo porque la articulación cognoscitiva del fenómeno revolucionario se involucra con los paradigmas intelectuales de la modernidad, entre los cuales se identifica la idea del progreso. En el mundo occidental, revolución y progreso alcanzan notoriedad en la evolución de las sociedades, siendo lo político el punto principal de enlace.

Hasta hoy, ninguna de las conquistas aparentemente insuperables, que en nombre de la democracia universalizó el liberalismo desde el siglo xix, mantienen al mundo a salvo de la constante amenaza de la quiebra política a que están sometidos los pueblos. De esta manera, su acción se halla condicionada por un conflicto sociopolítico como signo de crisis insuperable, que de acuerdo a nuestro juicio ha servido para identificar en la idea del precedente negativo el factor excepcionalmente justificante, y comprende el uso de la violencia en proporcionado grado y forma. Al propio tiempo, el soporte de su expresión es resultado de la vulneración de los principios de la racionalidad y del equilibrio político-constitucional establecido entre el Estado y sus ciudadanos y, en consecuencia, es determinante en el espacio de sus relaciones. Es desde esta perspectiva la resistencia política una actitud de cuestionamiento de las formas en que se ejerce el poder político y se realiza el derecho. 
De ahí que la primera pretensión de este estudio se encuentre orientada, necesariamente, a alcanzar una integración conceptual del derecho de resistencia que permita ubicarlo en el espacio de los derechos fundamentales, de acuerdo a la dominante perspectiva liberal positiva. Se trata, por tanto, de un fenómeno relativamente reciente el otorgar esta nominación. Esto hará posible, en un segundo momento, caracterizar el artículo 136 constitucional correlativo del "Título Noveno, de la inviolabilidad de la Constitución", en el ánimo de identificar qué principios de carácter normativo y qué ideas de la dogmática histórica están presentes en el reconocimiento constitucional de la resistencia política en México.

\section{La integración conceptual del derecho de resistencia en el pensamiento liberal positivo}

El derecho representa, en su lógica, la aspiración de satisfacer los ideales de justicia y seguridad por medio de la norma jurídica en primera instancia. De esta forma, cuando ocurre una fractura en ese orden provocada por la usurpación o la arbitrariedad del detentor del poder político, se valida el derecho a resistir tal estado de hecho fundado, que en el individuo opera como mecanismo intrínseco a su orden racional. Esta cualidad innata al ser ha recibido un especial tratamiento por la perspectiva liberal, al grado de que su juridificación ha adquirido valor definitivo por el medio constitucional, lo cual configura su corpus a través del derecho de resistencia. Es decir, desde una interpretación histórica, el Estado ha reconocido en el tejido de su orden jurídico la opción de resistencia en contra de sus posibles excesos de poder. Esto, al tiempo que presupone una conquista esencialmente popular, es una concreción limitada de hacer frente a la inseguridad política que aún no logran resolver las sociedades modernas.

La carencia de un sentido estricto de este derecho en la Antigüedad fue superada durante la Edad Media a través de un grupo de factores que inauguraron su tratamiento doctrinal, primero y su reconocimiento constitucional, después. Esta cualidad se transfiguró en dos etapas sucesivas con matices que han generado el cuestionamiento sobre su validez. La modernidad capaz de incorporarlo al régimen de los derechos humanos y el criterio positivista que desde la autonomía del derecho como norma negó de manera significativa su utilidad y por tanto, cercenó su desarrollo convirtiendo su esencia en política más que jurídica. Esta última circunstancia excluyó la razón moral valorativa en la formación del criterio jurídico sobre el derecho de resistencia. Tras esta dinámica se halla la zona de creación teórica postmoderna, que no soslaya el 
tema, y eleva en el foro su vitalidad y autonomía científica con una significativa infiltración ideológica. Este último juicio se valida a pesar del continuo e irreversible proceso de atomización y la consiguiente desconcentración del poder democrático que, en criterio de Gargarella, ${ }^{1}$ constituyen elementos imprescindibles a tener en cuenta en la tendencia revalorizada de la resistencia política.

De esta forma, dilucidar un esquema de sistematización lleva a relacionar un primer grupo de criterios de acuerdo al entorno moderno, ubicado desde el nexo histórico inmediatamente anterior a la Revolución francesa hasta la primera mitad del siglo xx. Aquí se ha visto armonizada la base del derecho de resistencia constitucional con los rasgos que se fueron orientando desde su formulación clásica, teniendo en cuenta la pertenencia a contextos históricos que hacen semejantes sus vías y formas de justificación. La diferencia más importante en relación a la etapa precedente ha estado identificada, tal como se ha visto, en torno a su normativización.

El segundo grupo se halla delimitado por un trazado periódico que comienza donde aquél termina, y alcanza los planteamientos contemporáneos donde pervive con carácter dominante la perspectiva liberal positiva. Sólo combinando estos contenidos - diversos, complejos, pero razonables- podría satisfacerse el interés cognoscitivo que nuestro objetivo presupone. Por tanto, el intento de alcanzar un concepto unívoco de derecho de resistencia pasa por reconocer estas cualidades, presentes en orden plural en la doctrina histórica europea y americana.

Para ello, en el orden metodológico ha sido conveniente el establecimiento de dimensiones. Esto hizo posible la descomposición en partes o extensiones, una mejor precisión terminológica y la representación de su integración funcional. Los contenidos que en atención a este criterio describen históricamente el derecho de resistencia son los siguientes:

1. La resistencia, sensu stricto, en su forma más primaria, como "derecho natural”, innato al ser. Semánticamente suelen emplearse como términos para referirse a la idea que supone la resistencia, v.gr. la violencia con que las personas pueden llegar a oponerse a un invasor o a una dictadura. ${ }^{2}$ Entender el fenómeno de la dictadura, de acuerdo a este contexto, conduce a una consecuencia de la crisis institucional del Estado, una ruptura -tal como la concibe

\footnotetext{
${ }^{1}$ Vid. Gargarella, Roberto, El derecho a resistir el derecho, Buenos Aires, clepp-Miño y Dávila Editores, 2005.

${ }^{2}$ En tal sentido el Diccionario de la Lengua Española, en su acepción más adecuada a nuestro fin define el término resistencia (Del lat. resistent a) como "Conjunto de las personas que, clandestinamente de ordinario, se oponen con violencia a los invasores de un territorio o a una dictadura."
} 
Burdeau - entre la idea del derecho y el poder, ${ }^{3}$ que es adecuado identificar con un estado de opresión política y no con la dictadura institucional de la república romana.

La resistencia es por tanto, en sí misma, una cualidad subjetiva, contestataria, no arbitraria, una actitud capaz de operar bajo circunstancias adversas que describen situaciones de injusticia social y opresión económica donde la represión política o tiranía actúa como el elemento más visible, detonante del estado de descontento popular como primera instancia valorativa del precedente negativo. Tal fenómeno se manifiesta independientemente de la voluntad del legislador y, como considera Moore, es preciso entenderlo a partir de la dinámica relación entre las reglas sociales y su violación como componentes fundamentales del agravio moral y del sentimiento de la injusticia. ${ }^{4}$ En política, su noción es identificada, de manera incontrovertible, con "la conservación de las instituciones consideradas como legítimas". ${ }^{5}$

Como cabe reconocer entonces, partir de un tratamiento axiológico de los derechos convoca al camino de entenderlos como un fenómeno derivado del consenso progresivo de la sociedad democrática, que es a su vez un producto del Estado de derecho y de sus garantías políticas. ${ }^{6}$

Entendido de esta forma, el iusnaturalismo se constituye como el primer componente lógico de la resistencia. En ello interviene un criterio valorativo de tipo metafísico, que respecto a la naturaleza humana la describe como una manifestación de su propia realidad y donde intervienen además, en atención al criterio de su libertad, elementos motivacionales de tipo psicocultural. ${ }^{7}$ Así, el individuo exterioriza una reacción consciente que al mismo tiempo estima como una facultad ejecutiva en virtud de defender su propia personalidad, coherente con un entorno institucional circunstancialmente agredido y, por tanto, afectado.

2. Como "forma ética de exteriorización de la conducta". La dimensión subjetiva de los derechos coloca en el centro de atención al individuo en sus relaciones particulares y, sobre todo, cuando se involucra con el poder político porque actúa controlándolo. Hay en sus contenidos una acción que se manifiesta cuando el bien libertad se encuentra amenazado en condiciones de opresión política, lo que es equivalente a colocar en riesgo un presupuesto esencial de la vida moral. Lo anterior implica una vocación eminentemente crítica de la

\footnotetext{
${ }^{3}$ Cfr. Burdeau, Georges, Traité de Science Politique, París, R. Pichon et R. Durand-Auzias, 1968, pp. 501-508.

${ }^{4}$ Véase Moore, BarRington, La injusticia: Bases sociales de la obediencia y la rebelión, México, unAm, 2007, pp. 27 y sS.

${ }^{5}$ Vitale, Ermanno, "Cambio político, Constitución y derecho de resistencia", Isonomía, No. 32, México, itam, p. 36.

${ }^{6}$ Pérez Luño, Antonio, Los derechos fundamentales, Madrid, Tecnos, 1988, p. 21.

${ }^{7}$ Cfr. GurR, Ted Robert, El porqué de las rebeliones, México, Editores Asociados, 1974, pp. 120 y ss.
} 
ética que se conecta socialmente con los principios de la validez jurídica y se orientan a combatir toda forma de injusticia mediante la inclusión de la moral en el derecho. La forma en que es concebida la resistencia en el espacio de lo público, en cuanto a límite de su propia actuación, deviene en prueba de eticidad en el actuar político.

Tal reconocimiento conforma el elemento primario axiológico y de derecho natural en la composición funcional del derecho de resistencia. Hay en ello una postura diametralmente opuesta a la cosmovisión kelseniana, resultado moderno y novedoso con un esquema de lo cognoscible, con una forma de pensar, concebir y creer en el derecho como ciencia, y con lo cual la política se continuará involucrando con protagónica intervención.

3. Como "derecho fundamental". Del reconocimiento del presupuesto constitucional dependerá su existencia. En la configuración del Estado moderno, es ésta una característica esencial que tiene su génesis en los procesos revolucionarios de fines del siglo xviII.

La solución de juridificar la resistencia política, que en el siglo xx concluye, determina la respuesta a la pregunta "para qué se resiste”. Aquí se va a producir la escisión entre la denominación "derecho de resistencia” (resistir para conservar) de la otra forma de resistencia política que interesa a este estudio, que es la "revolución" (resistir para trascender). Con esto se ocasiona también la quiebra definitiva de la noción clásica "derecho de resistencia a la opresión" como fenómeno latente en la capacidad de los pueblos de destronar reyes tiranos desde su más antigua concepción. Este derecho, que fue moral e intelectual primero, terminó siendo desnaturalizado con su juridificación. Desde entonces, derecho de resistencia y revolución constituyen dos conductas auto-excluibles.

Interesante es que todo esto cristalizó en la Constitución cubana de $1940^{8}$ antes que en ninguna otra parte. Su contexto, por sí mismo, habla de la presión democrática de la cual el derecho de resistencia fue un resultado muy concreto. En 1949, la Ley Fundamental de la República Federal de Alemania ${ }^{9}$ reafirma

\footnotetext{
${ }^{8}$ Pichardo, Hortensia, "Constitución de la República de Cuba, Convención Constituyente de 1940", en Documentos para la Historia de Cuba, tomo 4, La Habana, Cuba, Editorial de Ciencias Sociales, 1980, p. 338.

${ }^{9}$ Todo el primer título de esta Constitución (19 artículos) se dedica a los derechos fundamentales.. Llama la atención, sin embargo, que el derecho de resistencia se reconoce inmediatamente después, entre los fundamentos del orden de la Federación, véase Constituciones vigentes que reconocen el derecho de resistencia. Vale la pena apuntar que el carácter de fundamentalidad asignado a los derechos individuales se inaugura precisamente en Alemania, en la Constitución del 20 de diciembre de 1848, aprobada por la Asamblea Nacional en la Paulkirche de Frankfurt. Véase Pérez Royo, Javier, Curso de Derecho Constitucional, Madrid, Marcial Pons, 1997, p. 242. Su próximo reflejo tendrá lugar en Weimar (1919), en la Parte Segunda: Derechos y deberes fundamentales de los alemanes/Sección I: La persona individual (Artículos 109-118). Véase "Constitución del Imperio (Reich) alemán", 11 de agosto de 1919, en Textos Constitucionales españoles y extranjeros, Zaragoza, Athenaeum, 1930.
} 
este sentido en medio de la construcción del Estado democrático de derecho. Esto significa que en la progresión del "derecho de resistencia a la opresión", ocurre una bifurcación, un alto de carácter normativo cuando por primera vez se asigna el carácter de fundamentalidad a la resistencia política. En la evolución de esta institución se produce un punto de ruptura que, en lo adelante, deslindará de forma definitiva su función de otras formas de resistencia, como no había sido posible hasta este momento comprender en su cabal magnitud.

El derecho de resistencia, visto en este contexto del siglo xx, constituye una limitación positivada a la opción del enfrentamiento al poder arbitrario que hasta la configuración del pactum societatis se había manifestado asociada a la opción latente de la revolución. Ello es un resultado de la dominación del pensamiento liberal que alcanzó a enmarcar los límites del fenómeno de la resistencia política en la norma y, por lo tanto, restringirlo a como se conoce en la contemporaneidad. No obstante, como vale la pena apuntar, no es el normativismo un producto liberal. Llama la atención que esto ocurre en medio de un escenario que apuesta por el rescate de valores anteriores, cuando el fin de las guerras y del fascismo actuaron como soportes condicionantes de un hecho de extraordinaria importancia: el reconocimiento del recurso de la resistencia en su formulación clásica en la Declaración Universal de los Derechos Humanos.

De acuerdo al criterio de Pérez Royo, los derechos fundamentales son los derechos naturales constitucionalizados sobre la base del principio de la soberanía popular, para su eficacia directa, garantizados, protegidos e indisponibles para el legislador. ${ }^{10}$ También juega un papel decisivo, a juicio de Martha Prieto, el nivel de desarrollo y reconocimiento que, en relación con las aspiraciones y reclamos, cada sociedad haga de sus derechos y las garantías provistas para su defensa. ${ }^{11}$ En el ámbito de los derechos humanos, sin embargo, esta nomenclatura adquiere una multiplicidad de perspectivas.

Lo que parece importante subrayar aquí es que de acuerdo al carácter otorgado por la perspectiva liberal positiva, el acto de la resistencia política, en su dimensión formal y en primera instancia, tiene que quedar obligatoriamente ligado a la Constitución por una relación de dependencia sin la cual no habría

\footnotetext{
${ }^{10}$ Este autor, que ignora el acontecimiento cubano de 1940, considera que el criterio fundamental aplicado a los derechos de esta indole queda zanjado en Alemania (1949) por medio de las siguientes garantías: 1. Eficacia directa; 2. Vinculación de los poderes públicos; 3. Indisponibilidad para el legislador; 4. Contenido esencial y 5. Control judicial. Coincidente con este esquema general se manifiesta el criterio de AsENSI SABATER, JoSÉ, Constitucionalismo y Derecho Constitucional - materiales para una introducción-, Valencia, Tirant lo Blanch, 1996, p. 107. Vid. Pérez Royo, Javier, Curso de Derecho Constitucional, Madrid, Marcial Pons, 1997, p. 256.

11 Prieto Valdés, Martha, "La defensa de los derechos: una necesidad en cualquier momento", en Álvarez-Tabío Albo, Ana María y Matilla Correa, Andry (Coord.), El Derecho Público en Cuba a comienzos del siglo xxı. Homenaje al doctor Fernando Álvarez Tabio, La Habana, Editorial uH, 2011, pp. 212-213.
} 
fundamento de validez, y mucho menos integración al principio de supremacía constitucional. Ello provee un contenido de carácter prescriptivo y garantista que justifica la conducta resistente mediante el rango de la máxima norma. No puede entenderse, y es la cuestión de mayor interés, como una idea extrajurídica. Al mismo tiempo, ocurre que la orientación de su eficacia es de tipo vertical, si son tomados como puntos de referencia el poder político público del Estado y el derecho del ciudadano, en este caso autorizado a realizar una acción positiva, material.

La manifestación de esto último equivale al reconocimiento de una herramienta que es reserva de libertad y del resto de las aspiraciones humanas en la comunidad política. Esto es, un reforzamiento del resto de los derechos. Delimitarlo entonces como una institución privilegiada y preeminente en el marco de los derechos subjetivos, superior en su significación dentro de la estimativa constitucional por su orientación devenida en mecanismo de defensa, equivale a confirmar, en segunda instancia, su fundamentalidad. El marco histórico en que se desarrollan estos criterios, apegados a la perspectiva liberal, determinan la razón por la cual el presente estudio acoge su caracterización y dimensionamiento. Sin embargo, es oportuno dejar constancia de que no se corresponde con el juicio que nos parece más adecuado.

Como es apreciable, su soporte, además de subjetivo (elemento primario), es estrictamente legal (elemento indispensable) en orden jerarquizado, vinculante y material. Ello es posible plantearlo porque el hombre convertido en ciudadano asume la capacidad otorgada por la comunidad política, en cuyo espacio se transfigura el derecho natural en norma y adquiere esta última una posición ponderada, necesaria. Por una parte, tal composición relaciona mediante la tutela necesidades, bienes, intereses y principios valorados como superiores, de máximo rango. ${ }^{12}$ Por otra, precisa de garantías a través de mecanismos externos, que es una cualidad derivada del reconocimiento de derechos de esta índole. Esto es, el conjunto de compromisos y obligaciones que institucional, procesal o socialmente, el Estado y la comunidad respectivamente asumen en su sustento, control, restricción en su reforma, defensa y reparación en caso

\footnotetext{
${ }^{12}$ De acuerdo al criterio de la teoría estructural de los derechos fundamentales de Robert Alexy, el reconocimiento del derecho de resistencia en el catálogo constitucional le confiere la cualidad de norma de derecho fundamental. Es decir, un derecho subjetivo considerado como fundamental tendrá que estar otorgado a través de la validez de una norma que, en la misma dimensión, sea fundamental. Ello confiere una posición en el sistema jurídico como extremos de máximo rango, máxima fuerza jurídica y máxima importancia del objeto. Véase AleXY, Robert, Teoría de los derechos fundamentales, Madrid, Centro de Estudios Políticos y Constitucionales, 2008, p. 48; Alexy, Robert, "Derechos fundamentales y Estado Constitucional Democrático", en AA.W., Neoconstitucionalismo(s), Madrid, Trotta, 2006, pp. 31-47. También cfr. Carbonell, Miguel, Los derechos fundamentales en México, México, unam-CndH, 2004, p. 11.
} 
de quebranto. Esta última cuestión refuerza su criterio material y fundamental, prevalente en la evaluación de sus contenidos de eficacia directa, vinculante y pública, y se identifica como elemento secundario de garantía. Históricamente, sin embargo, los criterios axiológicos y positivos sobre los derechos han sido contrastadamente abordados en la doctrina jurídica, cuando en realidad, puede arribarse a una postura conciliadora.

En el siglo XIx, Ihering ofrece una doble cualidad al deber de resistencia ${ }^{13}$ a una circunstancia normativa o política injusta: el individuo, por su propia estimación y por la motivación social del bien común, fenómeno asumido a través de la lucha por el derecho en las esferas individual y social. Ello es resultado de una conclusión indicada a la recuperación política de la sociedad usurpada por la las injusticia. Según esta razón, la corresponsabilidad de los componentes de la vida social se involucra en el fin primigenio de la legalidad $\mathrm{y}$, en consecuencia, ha de velar y resistir todo acto contrario a ello. Se funda en esta idea una cualidad que este estudio también acoge por constituir parte inseparable de la funcionalidad material del derecho de resistencia: el deber. De acuerdo a esta perspectiva, éste se orienta a universalizar la responsabilidad ciudadana en favor de enfrentar todo acto de violación de los principios básicos que informan el orden político y jurídico del Estado y la sociedad.

Por otra parte, de acuerdo a la interpretación de la moderna doctrina alemana sobre el derecho público, el derecho de resistencia puede ubicarse dentro del grupo de las garantías sociales que, aún sin tener una naturaleza estrictamente jurídica, sí forman parte del derecho positivo. Su fuerza esencial es, sin embargo, de contenido más moral y cultural que normativo, e igualmente se indica a la protección del orden jurídico e institucional del Estado. ${ }^{14}$ Tal dinámica se halla enmarcada en la aureola subjetivista que en pleno siglo xx se funda en Alemania y que es importante destacar aquí aunque, como antes se pudo apreciar, varias de las Constituciones de sus Estados federados, e incluso la Ley Fundamental de la Federación, asumen su cualificación como derecho fundamental y universal.

Por otra parte, Fernández de Velasco y Calvo entiende la capacidad de resistir a la opresión en su cualidad garantista en el derecho y, por tanto, avala su consagración constitucional. ${ }^{15}$ En términos semejantes se expresa Geamanu, en el orden de reconocer la calidad de seguridad que el derecho

\footnotetext{
${ }^{13}$ IHering, Rudolf Von, La lucha por el derecho, México, Coyoacán, 2011, p. 85.

${ }^{14} \mathrm{Cfr}$. Jellinek, George, Teoría general del Estado, Buenos Aires, Albatros, 1978, pp. 591-592.

${ }^{15}$ Véase Fernández de Velasco y Calvo, Recaredo, El derecho de revolución y la revolución conforme a derecho, Madrid, Imprenta Artística Española, 1914, p. 179.
} 
de resistencia ofrece en contra de la arbitrariedad gubernamental. ${ }^{16}$ Alberto Peyrano, Ossorio y Gallardo, Sampay y Vanossi consideran también prudente su reconocimiento en las condiciones del Estado de derecho ${ }^{17}$; mientras que Carvajal llega a reconocer la necesidad de una subclasificación como derecho de impronta confesional y de tipo laico. ${ }^{18}$

En sentido contrario se expresa otro nutrido grupo de importantes autores, y de forma coherente el pensamiento eclesiástico. ${ }^{19}$ Duguit, por ejemplo, limita a una cualidad teórica al derecho de resistencia, y en su reconocimiento jurídico halla una importante reserva de acuerdo a los principios del Estado de derecho, ${ }^{20}$ criterio semejante a los aportados por Esmein y por Duverger. El primero de ellos entendiéndolo como un fenómeno incompatible con el orden político desde la perspectiva francesa de 1789, mientras que el segundo es de la opinión que constituye una limitación al funcionamiento del Estado. ${ }^{21}$

Así también Barthélemy asume la teoría sobre la resistencia a la opresión en su dimensión política y, por tanto, niega su carácter jurídico. Desde esta perspectiva, sólo puede entenderse un derecho de resistencia políticamente

\footnotetext{
${ }^{16}$ Véase Geamanu, Grigore, La résistance a l'oppresion et le droti à l'insurrection, París, Les Éditions DomatMontchrestien, 1933, pp. 281 y ss.

${ }_{17}$ Véase Peyrano, Alberto, Derecho de resistencia, Buenos Aires, Imprenta de M. Viedma, 1945, pp. 60 y ss.; Ossorio y Gallardo, Ángel, Los derechos del hombre, del ciudadano y del Estado, Buenos Aires, Claridad, 1946, pp. 174-182; Sampay, Arturo Enrioue, El derecho de resistencia. Su inadmisibilidad en la Constitución del Estado de Derecho, Buenos Aires, La Facultad, 1938; Rodriguez Varela, Jorge R. y Vanossi, Alberto, "El derecho de resistencia" (Separata de Anticipo de Anales, Academia Nacional de Derecho y Ciencias Sociales, No. 34, Año XLI, segunda época, 1997, Buenos Aires), p. 58.
}

18 Véase Carvajal Aravena, Patricio, "Derecho de resistencia, derecho a la revolución, desobediencia civil", Revista de Estudios Políticos (Nueva Época), No. 76, abril-junio de 1992, Madrid, Centro de Estudios Constitucionales, p. 71.

${ }^{19}$ De acuerdo con la doctrina pontificia, la posición en relación a la resistencia política de súbdito contra gobernantes tiranos continuó manifestándose de forma casi invariable durante todo el siglo XIX, y expresaba un criterio en favor de la obediencia a la autoridad en tanto sus actos no quebrantaran la ley sagrada de Dios. Para casos de esta índole, la Iglesia Católica fijó la firme posición de declarar nulo todo acto proveniente del gobierno, siendo así proclive al desconocimiento por parte de los súbditos del Estado. Véase Carta Encíclica Diuturnum Illud, del Sumo Pontífice León XIII, Sobre la Autoridad Politica, Roma, 29 de junio de 1881. [Consulta: 25 de diciembre de 2015]. Disponible en: http://www.vatican.va/holy_father/leo_xiii/encyclicals/documents/hf_I-xiii_enc_29061881_diuturnum_sp.html Años después, con una abierta anuencia al derecho de desobedecer los mandatos de la tiranía, declara que "se presta obediencia a la más justa y elevada autoridad. Pero cuando no existe el derecho de mandar, o se manda algo contrario a la razón, a la ley eterna, a la autoridad de Dios, es justo entonces desobedecer a los hombres para obedecer a Dios. Cerrada así la puerta a la tirania, no lo absorberá todo el Estado. Quedarán a salvo los derechos de cada ciudadano, los derechos de la familia, los derechos de todos los miembros del Estado, y todos tendrán amplia participación en la libertad verdadera, que consiste, como hemos demostrado, en poder vivir cada uno según las leyes y según la recta razón." Carta Encíclica Libertas Praestantissimum, del Sumo Pontífice León XIII, Sobre la libertad y el liberalismo, Roma, 20 de junio de 1888, I.10. [Consulta: 25 de diciembre de 2015]. Disponible en: http:/l www.vatican.va/holy_father/leo_xiii/encyclicals/documents/hf_Ixiii_enc_20061888_libertas_sp.html

${ }^{20}$ Véase Duguit, LEón, Manual de Derecho Constitucional, Madrid, Librería Española y Extranjera, 1921, pp. 297-303.

${ }^{21}$ ESMeIN, AdHémAR, Éléments de Droit Constitutionnel francais et comparé, tomo II, París, Librairie de la Société du Recueil Sirey, 1921, p. 534; Duverger, Maurice, Cours de Droit Constitutionnel, París, Librairie du Recueil Sirey, 1946, pp. 135-136. 
legítimo, pero ni siquiera lo puede ser desde la justificación del derecho natural. ${ }^{22} \mathrm{~A}$ favor de ello, legitimidad sin legalidad sostiene en su análisis Reinhold Zippelius; ${ }^{23}$ mientras que Soler sólo reconoce al hombre en sociedad la libertad natural que le asiste de juzgar la norma y, por tanto, no acatarla. ${ }^{24}$ Fayt, por su parte, le otorga un simple carácter supra positivo, sólo inscrito "en el corazón y en la razón de los hombres". ${ }^{25}$

De esta manera, se propició un nuevo ciclo de discusión teórica. Las nuevas cualidades del Estado inaugurado en la Modernidad debido a sus mecanismos de sustento, integralidad y continuidad constitucional, impiden que sean propicias condiciones de opresión política; reconocido además el progresivo avance en materia de derechos políticos hacia sociedades más conscientes y participativas. Después de la Revolución francesa, la burguesía pretendió imponer la idea de que la democracia era un producto creado en su contexto, lo cual, obviamente, es falso. Esto surge en el ánimo de despojarla de su sentido original, y colocarla a merced de sus intereses, lo cual es fundamental para entender el nuevo papel otorgado a la resistencia, marginada desde luego ante el empuje de todo el sistema de representación, sufragio universal y control de la constitucionalidad que paulatinamente se superponen en forma de paradigma para anular su utilidad, como en sentido general también funcionó para limitar la expansión y materialización de los derechos al margen del control político.

Tal interpretación promueve la idea de que es posible prescindir del derecho de resistencia. El anterior fue el criterio predominante durante la apertura y desarrollo del siglo xx, en especial sobrevenida la consolidación del Estado liberal positivo. En este periodo, Bobbio niega la cualidad de derecho a la resistencia política. Le atribuye, derivando su interpretación de lo estipulado en la Declaración Universal de los Derechos Humanos, un carácter de necesidad derivativa y, por tanto, secundario. ${ }^{26}$ Ya con menor aspereza, Recasens Siches juzga este sentido otorgándole el carácter de derecho natural, racional, ideal, como un principio de axiología jurídica. ${ }^{27}$

Sin embargo, como advierte Vitale, más allá de todas las garantías que ofrecen sustento y protección al sistema constitucional contemporáneo, el peligro de su violación no deja de evidenciar el riesgo latente de una fractura institucional profunda. Sobre este criterio reconoce, en primer lugar, la

\footnotetext{
${ }^{22}$ Véase BARTHÉlemy, JoSePH, Traité élémentaire de droit constitutionnel, Paris, Dalloz, 1926, p. 243.

${ }^{23}$ Véase Zippelus, Reinhold, Teoría general del Estado, México, unam, 1985, pp. 157-158.

${ }^{24}$ Véase Soler, Sebastián, Ley, historia y libertad, Buenos Aires, Losada, 1943, pp. 91-92.

${ }^{25}$ Fart, Carlos S., Derecho político, tomo 2, Buenos Aires, Depalma, 1998, p. 145.

${ }^{26}$ Bobbio, Norberto, El tiempo de los derechos, Madrid, Fundación Sistema, 1991, p. 141.

${ }^{27}$ Véase Recasens Siches, Luis, Tratado general de filosofía del derecho, México, Porrúa, 1975, p. 621.
} 
legitimidad moral del uso del derecho de resistencia y, más esencialmente, el significado de que, con su reconocimiento, se estaría añadiendo un mecanismo adicional de protección a la Constitución, validez y continuidad, frente a cualquier intento de subvertirla. ${ }^{28}$

En este análisis, si bien es cierto comprender que el Estado de derecho es una construcción concebida para la "no excepcionalidad", como considera Ferrajoli, no es descabellado de ningún modo encontrar las aristas de compatibilidad que el derecho de resistencia reviste para situaciones de otro tipo, esto es, excepcionales. Visto así, su reconocimiento equivale a una figura que favorece la garantía, legitimable en manos del ciudadano en los casos en que sea vulnerado el "pacto constitucional". Es por ello que asociar a Ferrajoli con una postura incontrovertiblemente opuesta al derecho de resistencia ofrece una idea inexacta. En todo ello, comprender la primera imagen como absoluta (Estado de derecho como construcción "no excepcional"), se convierte en un ideal que ciertamente el propio Ferrajoli identifica con el "paradigma constitucional”. Pero lo cierto es que, en ninguno de los tractos históricos de la humanidad hasta hoy, se ha podido verificar una consecución uniforme y armoniosa de esta idea en todos los sistemas de derecho en el mundo. Todo lo contrario, cada vez se encuentran más amenazados por los desequilibrios de la era global, dificultad que este autor no deja de reconocer. Esta razón, en su momento no menos latente, le permitió a Schmitt definir la razón del estado de excepción, ${ }^{29}$ producto francés que Ferrajoli imputa como "la inversión del modelo del Estado de derecho: la primacía del poder político sobre el derecho". ${ }^{30}$ En estas condiciones, encuentra refuerzo el criterio del deber.

Cabe, por último, siguiendo las razones que favorecen la fundamentalidad del derecho de resistencia dentro de los marcos de la perspectiva liberal, advertir cuatro posibles subclasificaciones: 1 . Según su contenido, de seguridad; 2 . Por la forma de prestación, derecho-deber; 3. Por sus titulares, individual/colectivo y 4. Por su ámbito de aplicación, nacional. En este punto, es posible también dimensionar sus elementos configuradores: objeto: mecanismo de defensa constitucional, de salvaguarda y seguridad del orden político y jurídico del Estado; sujeto: ciudadanos con capacidad de obrar; contenido esencial: legitima la acción de enfrentamiento contra los actos de violación de los derechos, así como de los principios básicos del orden político e institucional del Estado;

\footnotetext{
${ }^{28}$ Véase Vitale, Ermanno, "Cambio político, Constitución y derecho de resistencia", Isonomía, No. 32, México, itam, abril de 2010, pp. 41-47.

${ }^{29}$ Véase SCHMIT, CARL, La dictadura desde los comienzos del pensamiento moderno de la soberanía hasta la lucha de clases proletaria, Madrid, Alianza, 2003; Schmirt, CARL, Teología política, Madrid, Trotta, 2009, p. 37.

${ }^{30}$ Ferrajol, Luigl, Principia iuris. Teoría del derecho y de la democracia, tomo 2, Madrid, Trotta, 2011, pp. 101-102.
} 
límite: proporcional en su ejercicio a la causa que lo activa; sistema de garantías: normativa o abstracta (rigidez constitucional, contenido esencial) y social (la participación popular que conserva la capacidad soberana de desarrollar las acciones de la resistencia política).

4. Como "expresión excepcional y proporcional" correspondiente a situaciones "extremas". Los contextos de esta envergadura implican un grave peligro para la supervivencia del orden constitucional del Estado, lo que, como se ha dicho, equivale a la primera instancia valorativa del precedente negativo.

Ahora bien, es preciso anunciar que visto así, no se alcanza aún su completitud. Para que ello ocurra, el ejercicio del derecho de resistencia ha de tener como supuesto necesario la completa configuración del precedente negativo, que se produce con la utilización y agotamiento de las formas de resistencias institucional, sociopolítica y legal. Ello constituye su segunda y última instancia valorativa y permite, en este momento y gracias al carácter progresivo de su conformación, asignar una naturaleza estática, esto es, completa, conceptual, a este fenómeno. A los efectos de la investigación, estos criterios, descompuestos, deben ser entendidos de la siguiente manera:

- Opresión política implica un ejercicio del poder contrario al bien común, donde perviven como sustratos la opresión económica y social; constituyendo la tiranía una manifestación extrema que actúa como detonante del descontento social.

- Resistencia institucional se identifica en la base de articulación del poder público, cuya razón obliga a sus funcionarios (designados y elegidos) a su defensa y salvaguarda en virtud de sus cargos y responsabilidades administrativas.

- Resistencia sociopolítica es la oposición manifiesta a través de conductas cívicas en cuya externalización se evidencia la no violencia (protesta pública, denuncia, desobediencia y mediación) promovidas, legítima y esencialmente, por el ámbito social de la ciudadanía y el sistema político (órganos, grupos, partidos políticos).

- Resistencia legal es la oposición que se manifiesta en los planos jurídicos formales, lo cual remite a comprender las opciones estrictamente legales (vía judicial) habilitadas y utilizadas con el fin de promover la anulación de la situación de opresión o tiranía y consecuentemente restaurar el orden constitucional transgredido.

Derivado de esto, la consecución del derecho de resistencia puede ser representada así: Situación reconocida por el orden jurídico - precedente negativo 
identificado en forma de causa - acción de resistencia proporcional como derecho ejercitado (conducta autorizada) - resultado jurídico válido.

En esta lógica se halla una relación de índole causal cuyo contenido es además limitado. En ello, es conveniente asumir un enunciado condicional en virtud del cual la resistencia política adquiere una dimensión de excepción, provocando una ruptura ${ }^{31}$ cuando no resulta disponible ningún otro medio social, político y legalmente concebido para la defensa y salvaguarda del ordenamiento jurídico. En ese tracto, debido a que sus formas estipulan el ejercicio de la violencia (que exonera en este caso la responsabilidad penal), su uso debe ser entendido como recurso de ultima ratio.

Así, el derecho de resistencia debe manifestarse proporcionalmente a la situación que provoca su ejercicio (relación entre el daño social que provoca el acto de opresión y el resultado de la actividad de resistencia). Al mismo tiempo, observar que no sean vulnerados otros derechos, lo cual presupone no sólo un importante elemento de su cualidad argumental, justificante y de legitimación, sino también de sus límites. De acuerdo a este criterio, el derecho de resistencia, que en sí mismo es también una vía de defensa del resto de los derechos reconocidos con idéntica categoría, no podría inobservarlos o irrespetarlos. La atención teórica y práctica al concepto de proporcionalidad involucra al conjunto de garantías y a los esquemas con que éstas se reflejan entre los operadores del derecho encargados de su interpretación. De manera que, tanto la situación del precedente negativo como la necesidad de los medios utilizados indicados al fin, deberán ser sometidos de conjunto al examen de la proporcionalidad en virtud de determinar su validez.

Por último, se excluyen de su ámbito otras formas pasivas que en ocasiones se identifican confusamente análogas, como la objeción de conciencia y la desobediencia civil, auspiciadas individual o colectivamente.

5. Como "forma de control del poder político desde sí mismo". El poder público que detenta el Estado lo convierte en una persona jurídica especial de acuerdo a la estimativa del derecho. Su configuración orgánica representa una voluntad cuyo origen se halla en la doctrina sobre los derechos públicos. Es, asimismo, responsable ético de la conciencia popular, siendo lo jurídico la forma que en esencia valida su exteriorización.

De acuerdo a estos principios, el Estado constitucional concibió incluir entre sus formas de generación político-jurídicas al derecho de resistencia como límite a esa voluntad, y es delimitado a su vez por los resortes de su

\footnotetext{
${ }^{31}$ Bobbio ofrece a la ruptura un juicio de valor fundamental en la comprensión del fenómeno de la resistencia política. Según este criterio, ésta se halla dirigida "contra el orden constituido" que "ha puesto en crisis al sistema".
} 
legalidad y proporcionalidad. En ello, la oportunidad de la resistencia política cobra especial sentido práctico, pero a su vez es limitada al hacerse depender del reconocimiento, lo cual describe su dimensión objetiva y positivo-formal cuando en realidad se produce un compromiso institucional de proteger la vigencia plena del derecho.

De acuerdo a la idea del precedente negativo, la resistencia política adquiere la capacidad de erigirse como un mecanismo de control del poder -desde sí mismo por medio del reconocimiento positivo- si en ello entendemos una cualidad inmanente del límite. Por su propia naturaleza, su tendencia está dirigida a la sanción o revocación, en este caso del poder político ejercido inadecuadamente, lo cual complementa la composición funcional del derecho de resistencia mediante el elemento secundario de control. En ese sentido, si bien es cierto, como considera Pérez Royo, que el poder del Estado asume el monopolio de la coacción física legítima, ${ }^{32}$ el diseño del derecho de resistencia permite contener cualquier variación anómala en esta naturaleza; esto es, su extralimitación y crisis. La idea parte de la respuesta a posibles manifestaciones institucionales o legales injustas, equivalente a "la razonabilidad de la justicia" según la consideración de Rawls. ${ }^{33}$

6. Como "forma de salvaguarda y defensa del orden constitucional". Este criterio resume y cierra el ciclo multiforme de la esencia jurídica del derecho de resistencia, lo cual al mismo tiempo refuerza su formulación jerárquica en el ámbito de los derechos fundamentales. El uso adecuado de sus formas deberá siempre estar dirigido a la defensa de la integridad del orden constitucional, si ello es entendido como medio destinado a prevenir-impedir-restaurar la violación de la Constitución y, en consecuencia, a propiciar la anulación de la circunstancia opresiva contraria a sus principios básicos. Esto es, enfrentarse legalmente a la opresión que entraña una norma o acto inconstitucional cuando interesan a los derechos fundamentales y, por tanto, afecten a la comunidad política; siempre en última instancia y cuando el resto de los medios de defensa constitucional hayan resultado ineficaces. Tal interpretación es esencialmente garantista en forma de rasgo especial de su construcción positiva, confirma el principio de ultima ratio y conserva toda la utilidad que el Estado de derecho otorga a los ciudadanos para su propia custodia; criterio en el que manifiestan acuerdo autores como Schmitt y Dworkin. ${ }^{34}$ Pero aún es interesante que, dentro

\footnotetext{
32 Pérez Royo, Javier, Curso de Derecho Constitucional, Madrid, Marcial Pons, 1997, p. 67.

${ }^{33}$ Cfr. Rawls, John, Teoría de la justicia, México, Fondo de Cultura Económica, 1979.

${ }^{34} \mathrm{~A}$ juicio de Schmitt, el derecho de resistencia ofrece la posibilidad de que cada ciudadano pueda ser "considerado como un eventual protector de la Constitución", lo cual le hace ver como "una extrema garantía". Véase Schmir, CARl, La defensa de la Constitución. Estudio acerca de las diversas especies y posibilidades de salvaguardia de la
} 
de esta lógica, otros como Lucas Verdú y Ugartemendía incorporen la cualidad del deber ${ }^{35}$ como una transfiguración dual que al mismo tiempo es entendida como forma de garantía constitucional. En cualquiera de sus manifestaciones será siempre de orden no jurisdiccional y extrema; asumiendo entonces un compromiso solidario y vinculante entre los miembros de la comunidad política en forma de complemento de su poder positivo. De acuerdo a estos elementos, el reconocimiento constitucional de la resistencia política conforma una funcionalidad múltiple descrita como derecho-deber-garantía. En ningún caso, por tanto, el derecho de resistencia podrá hacerse equivaler a un ideal de derribar el orden político y edificar en su lugar uno nuevo.

Con esta visión, la resistencia es una cualidad innata al ser, una forma de juicio valorativo con expresión múltiple, y es, a su vez, una manifestación de libertad individual. Su socialización la convierte en un fenómeno trascendente al espacio particular, ocurriendo un proceso de transfiguración política. Éste necesita ser tutelado jurídicamente por el orden estatal, ya sea observándolo, aceptándolo o condenándolo, pero en cualquier caso, debe ser reconocido. La evolución histórica de la sociedad política permite asumirlo como un derecho, deber y garantía del orden constitucional que no podrá expresarse per se, sino en virtud del precedente negativo que valida las condiciones de la excepcionalidad justificante. La historia es consecuente en señalar en la injusticia la base causal de la resistencia como fenómeno humano propio, reflejado en el ámbito sociopolítico no pocas veces en la evolución de las sociedades.

El liberalismo decimonónico, que defendió a ultranza el robustecimiento del poder, legó al siguiente siglo la funcionalidad de la resistencia política orientada a la defensa constitucional, como resorte de estabilidad y en nombre aparentemente de la democracia. En todo ello incidió de manera notable la experiencia histórica francesa conectada con la superación del absolutismo y

Constitución, Madrid, Tecnos, 1983, pp. 55-56. En atención a este mismo criterio, Dworkin considera que quienes actúan haciendo uso de las diferentes modalidades del derecho de resistencia están orientados en la vocación del restablecimiento de los demás derechos y fines del Estado colocados en peligro, más que para atacarlos. Es una conducta que se vuelve legítima desde el propio acto de la consciencia y, por tanto, no debe ser castigada por el derecho. Véase Dworkin, Ronald, Los derechos en serio, Editorial Ariel, Barcelona, 1984, pp. 276 y ss. En sus estudios sobre el tema, también Jorge Peirano ubicó el objeto principal del derecho de resistencia indicado a la protección al resto de los derechos jurídicamente reconocidos, y a la salvaguarda de la Constitución. Véase Peirano Facio, Jorge, El derecho de resistencia, Uruguay, Talleres Gráficos 33, 1945, pp. 64-65.

${ }^{35}$ Como reconocen autores como Lucas Verdú y Ugartemendia, el Estado constitucional democrático brindó una nueva dimensión a los contenidos del deber constitucional, ya presentes en el Estado liberal. A esta lógica pertenecen las formas de resistencia concebidas, orientadas a la defensa del sistema político como bien jurídicamente protegido, mediante la asunción del derecho-deber. Véase Lucas Verdú, Pablo y Murillo de la Cueva, Pablo Lucas, Manual de derecho político, vol. 1, Madrid, Tecnos, 2000, pp. 78-79; Ugartemendia Ecelzabarrena, Juan Ignacio, "El derecho de resistencia y su constitucionalización", Revista de Estudios Políticos, No. 103, Madrid, Centro de Estudios Constitucionales, enero-marzo 1999, pp. 237-238. 
las bases de la Ilustración, así como el rechazo al deber de obediencia de la ley de acuerdo al fundamento de la razón de Estado por una parte, y la consagración de la teoría de la soberanía colectiva (popular y de la nación), por otra.

De acuerdo entonces a los elementos dimensionados, se entiende el derecho de resistencia como un derecho fundamental que, partiendo del precedente negativo y del plano de la subjetividad, se convierte en un medio extremo de garantía constitucional orientado a la defensa del sistema político ante situaciones graves de violación de sus principios básicos. El mismo puede adquirir diversas formas de manifestación, proporcionalmente indicadas en usos violentos, actuando como eximente de la responsabilidad penal por resistir a la opresión. Sus signos, absolutos e indispensables -tal como ocurre con el resto de los derechos de esta índole- serán su personalismo, su universalidad, su irrenunciabilidad, su imprescriptibilidad, su inviolabilidad y su orientación inalienable pero, de forma muy singular, su excepcionalidad. No puede haber confusión entre concepto teórico y regulación normativa. Ambas ideas han de manifestarse conjuntamente en el plano del reconocimiento, y han de estar dirigidas, como principio, a la conservación y salvaguarda del orden jurídico y político consagrado en la Constitución. En esta cuestión, como se ha dicho, ha jugado un papel dominante la interpretación de la perspectiva liberal positiva.

Entendido de esta forma, el derecho de resistencia deviene en mecanismo de defensa constitucional. En la estructuración de sus componentes, se ha debido tomar una posición integradora, sistémica, no excluible, mediante la imbricación del elemento legal indispensable con los elementos axiológico y de derecho natural (primario) y de garantía y control (secundarios). Como consecuencia, la sistematización de sus más sobresalientes presupuestos iuspolíticos e históricos ha permitido distinguirla como una institución autónoma de carácter jurídico evolucionada hasta la modernidad como una manifestación de resistencia política cuyo tronco es la noción clásica del derecho de resistencia a la opresión.

\section{La resistencia constitucional en México}

Corresponde por último examinar qué ocurrió con el tratamiento jurídico ofrecido a la resistencia política en el contexto de la Constitución Política de los Estados Unidos Mexicanos, otorgada por el Congreso Constituyente de Querétaro el 5 de febrero de 1917. Si bien su breve preámbulo evidencia que la Carta Magna constituye legítimo resultado de una larga tradición de resistencia, y ella misma se enmarca en lo que conceptualmente podríamos acoger como una Constitución revolucionaria, no existe en su articulado ninguna referencia explícita reguladora en torno a la cuestión de la resistencia 
política. No significa esto, sin embargo, que sus contenidos no puedan ser identificados como parte de una intencionada manifestación de protección que mediante la forma constitucional prevé la sostenibilidad en el tiempo de la propia norma. En la agenda del constituyente fue este un asunto que mereció atención, y su instrumentación tuvo lugar por medio del artículo 136, cuyos términos sustentan que:

Esta Constitución no perderá su fuerza y vigor, aun cuando por alguna rebelión se interrumpa su observancia. En caso de que por cualquier trastorno público se establezca un gobierno contrario a los principios que ella sanciona, tan luego como el pueblo recobre su libertad, se restablecerá su observancia, y con arreglo a ella y a las leyes que en su virtud se hubieren expedido, serán juzgados, así los que hubieren figurado en el gobierno emanado de la rebelión, como los que hubieren cooperado a ésta. ${ }^{36}$

Como es posible advertir de su lectura, son de variado signo y provecho para el análisis los elementos que se relacionan, de manera que la descomposición de sus contenidos ayudaría a delimitar la intención de nuestra contribución.

En correspondencia con este esquema, son tres los contenidos que, interdependientes, amparan la cuestión de la resistencia constitucional y que merecerán nuestra atención en lo que sigue a manera de conclusiones:

- El derecho de resistencia es una cualidad extrajurídica;

- La deconstrucción normativa del derecho a la revolución como lógica del Estado de derecho;

- La Revolución como fuente de derecho y el derecho de la revolución.

\section{El derecho de resistencia es una cualidad extrajurídica}

En la Constitución mexicana, el uso del término "rebelión" adquiere una especial connotación. De ello debemos evidenciar una marcada diferencia conceptual con la revolución de la que fue origen el propio texto constitucional. En todo esto, entender el valor del proceso revolucionario ligado a la cuestión de la legitimidad y a la idea del progreso permite, en este punto, deslindar su esencia

\footnotetext{
${ }^{36}$ Constitución Política de los Estados Unidos Mexicanos, publicada en el Dof el 5 de febrero de 1917, (texto vigente reformado hasta el 29 de enero de 2016), artículo 136, Cámara de Diputados del Honorable Congreso de la Nación, p. 140. [Consulta: 5 de marzo de 2016]. Disponible en: http://www.diputados.gob.mx/LeyesBiblio/pdf/1_29ene16.pdf
} 
de cualquier otro intento que implique un cambio, como expresión de tránsito o simple movimiento. ${ }^{37}$ De acuerdo a esta concepción, no será revolución cualquier proceso violento que, surgido de la sociedad, sea capaz de producir una rebelión contra el Gobierno y como consecuencia, logre sustituirlo por otro, ${ }^{38}$ juicio que se corresponde con conocidas perspectivas teóricas. ${ }^{39}$

Conectado con este primer orden de ideas en el que ha sido preciso detenerse, el artículo 39 constitucional nos dice: "La soberanía nacional reside esencial y originariamente en el pueblo. Todo poder público dimana del pueblo y se instituye para beneficio de éste. El pueblo tiene en todo tiempo el inalienable derecho de alterar o modificar la forma de su gobierno".

Es en este punto interesante plantearse la pregunta de si es posible comprender en el rango de interpretación que nos ofrece la Constitución la idea de la resistencia política en la dimensión revolucionaria. La lectura del artículo 39 es útil a los efectos de este planteamiento, pues el pueblo mexicano tendría en todo momento la posibilidad de "alterar o modificar" la forma de su gobierno, que es en puridad una cuestión primaria del contenido constitucional. Sin embargo, la canalización de este derecho tendría en el artículo 135 su límite establecido por vía de la reforma, posibilidad únicamente reservada al Congreso de la Unión, que debe contar con la mayoría de las legislaturas de los estados y de la Ciudad de México.

Si la soberanía es efectivamente un resultado del reconocimiento del pueblo como hacedor de su suerte, la resistencia bien podría ser un vehículo de ajuste, eficaz y democrático, para sostener y defender el buen ejercicio del poder político mediante un mecanismo técnico que precisa de su reconocimiento para su activación legal. Pero tal y como se encuentra planteado, no queda del todo explícito si la cuestión de la resistencia política es posible en el ejercicio fáctico de los derechos, de manera que ésta queda delimitada al rango de un derecho natural, no juridificable.

Hay en todo esto una cualidad que es preciso involucrar con la cuestión de la ética en los manejos de la política, la participación y los derechos. La ruptura del pacto implícito, que en el valor de la legitimidad y observancia de la Constitución supone el irrespeto del Estado y su sistema institucional

\footnotetext{
${ }^{37}$ De acuerdo a este criterio, se entenderian como tipos simples de movimientos a las revueltas, rebeliones, golpes de Estado, motines, cuartelazos, disturbios internos y otros de indole similar. Véase CarpIzo, Jorge, "Constitución y revolución", Revista de la Facultad de Derecho de México, tomo 20, No. 79-80, julio-diciembre de 1970, unam., pp. $1150-1151$.

${ }^{38}$ Ortega y Gasset, JosÉ, "El ocaso de las revoluciones", en El tema de nuestro tiempo, Buenos Aires, Espasa-Calpe, 1938, pp. 111-112.

39 Véase Linares Quintana, Segundo V., Tratado de la ciencia del derecho constitucional argentino y comparado, tomo 6, Buenos Aires, Alfa, 1956, pp. 246 y ss.
} 
de los deberes en la gobernanza, implica la activación de la resistencia en materia política. Ésta, que puede ser de diverso grado de acuerdo a los niveles jurídicamente establecidos, puede alcanzar en forma de recurso de ultima ratio la vía violenta cuando no sean respetados sus recursos precedentes. En tal situación de déficit democrático, la resistencia política es directamente proporcional al deber ciudadano de satisfacer sus propios derechos, y actúa imputando la legitimidad del Estado. Por tanto, también implica una quiebra en sus consensos, del mismo modo que en sus orígenes, el constitucionalismo legó a la posteridad en forma de valor.

Es preciso, en todo esto, que no escape a nuestra vista otra cuestión que merece involucrarse: la resistencia vista como delito. Apercibiéndonos de que no existe alusión al delito político en el texto constitucional, ${ }^{40}$ es este un tema de profundas consecuencias, dado que, en forma severa, el Código Penal Federal de México en sus Capítulos III, IV y V (artículos del 130 al 138) tipifica y sanciona las conductas de sedición, motín y rebelión, ${ }^{41}$ manifestaciones de resistencia que equivalen a la nominación de delito político según establece el artículo 144. Tal conducta, como resulta lógico entender, ha sido seguida por la Suprema Corte de Justicia en oportunidad de dejar fuera de este rango de interpretación al genocidio y al terrorismo..$^{42}$ Quiere esto decir que la referencia constitucional al delito político -aún sin conceptuarlo- es complementada por la norma penal y por la ejecutoria en materia de administración de justicia, en buena medida un resultado coherente del ordenamiento jurídico e institucional de México.

Queda fuera de toda duda, en todo esto, que hay una expresión de delito grave contra la seguridad de la nación como bien jurídico tutelado y, al mismo tiempo, un posible derecho ejercitable a partir del postulado constitucional que pudiera quedar vulnerado mediante la penalización de sus conductas. En el entendido de que el poder político fundado en los derechos es poder político legítimo,$^{43}$ la restricción jurídica de la resistencia política en la sociedad mexicana actual constituye un contrasentido. Sobre todo si en ello tenemos en cuenta el papel que ha correspondido a la sociedad civil, en donde se implican, junto al sistema jurídico, las redes de movimientos sociales y de asociaciones de

\footnotetext{
${ }^{40}$ Sólo el artículo 73 fracción XxI otorga competencia al Congreso de la Unión para expedir "la legislación que establezca los delitos y las faltas contra la Federación, y las penas y sanciones que por ellos deban imponerse".

${ }^{41}$ Código Penal Federal, publicado en el DOF el 14 de marzo de 1931 (texto vigente reformado hasta el 7 de abril de 2016), Cámara de Diputados del Honorable Congreso de la Nación, pp. 31-32. [Consulta: 5 de mayo de 2016]. Disponible en: http://www.diputados.gob.mx/LeyesBiblio/pdf/9_070416.pdf

${ }^{42}$ Tesis P. II/2003 (Genocidio. No es delito político), Semanario Judicial de la Federación y su Gaceta, tomo 17, junio de 2003, p. 6; Tesis P. IV/2003 (Terrorismo. No es delito político), Semanario Judicial de la Federación y su Gaceta, tomo 17, junio de 2003, p. 7.

${ }^{43}$ Agultó, Josep, "Sobre el constitucionalismo y la resistencia constitucional", Doxa. Cuadernos de Filosofía del Derecho, No. 26, Alicante, 2003, p. 293.
} 
carácter civil, político y cultural, con una fecunda tradición de luchas, diversas pero convergentes en el sentido de las garantías de la justicia, la democracia, la tolerancia, el equilibrio político y la paz social.

De esta forma, el debate se torna más agudo, e involucra adicionalmente el cuestionamiento de si es la resistencia política, en definitiva, un derecho al margen del sistema axiológico positivado por la Constitución, o si es la propia Constitución una norma resistente al cambio por vía distinta a la establecida en su artículo 135. Esto último, parece claro, determina una posición dominante, una especie de valor superior, que complementado en este análisis con la normativa penal pareciera desconocer la vitalidad con que un derecho de esta magnitud se encuentra recogido en el preámbulo de la Declaración Universal de los Derechos Humanos. La Constitución mexicana revela así un reconocimiento implícito a la cuestión de la resistencia política, concebida por tanto en forma de derecho natural, no juridificable, lo cual no es, de ningún modo, un fenómeno raro en nuestra región. Es abundante identificar esta intención - a veces ausencia - en la mayoría de los textos constitucionales de América Latina, lo mismo que en el resto del mundo.

Vistas hasta ahora este grupo de ideas, vale la pena en este punto considerar la cuestión del vacío constitucional que el artículo 136 prevé en su letra, por razón de la instauración de un gobierno derivado de "cualquier trastorno público”. Como más adelante se verá, el Estado moderno ha adoptado la idea, dominante en el escenario liberal positivo, de la deconstrucción normativa del derecho a la revolución. Ello se corresponde precisamente con la intención de salvaguardar el equilibrio y el sostenimiento en el tiempo de la propia ley constitucional, y es un criterio adoptado por el constituyente mexicano de 1917.

Como antes ya vimos, la legislación federal en materia penal es clara en la complementación de esta idea, al tipificar y punir los delitos que atenten contra la seguridad de la nación e importunen el normal desenvolvimiento y eficacia de la constitucionalidad, así como de los órganos y las instituciones del Estado y el Gobierno. Pero es la rebelión, dentro de este marco, la conducta que mayor atención recibe, debido a su alcance y orientación a la trascendencia política. La limitación de la idea que se define, sin embargo, se encuentra en el supuesto de que toda acción involucrada con la rebelión quede derrotada $\mathrm{y}$, por consiguiente, no quede abolida la Constitución y sus responsables sean juzgados. Ello perdería toda fuerza en la circunstancia en que, por el contrario, la rebelión derivara en un proceso revolucionario capaz de instituir un nuevo régimen político, social, económico y por consiguiente, también jurídico. Esto es, la necesaria relación que históricamente se ha establecido entre Revolución y Constitución, tan preconizada en los más importantes saltos políticos del mundo 
moderno. En este análisis se involucran interdependientemente las formas en que se ejercen la autoridad y el poder político, la democracia, los derechos, la participación, todos en un entorno global cada vez más dispar y en el que, por tanto, los sectores más empobrecidos siguen siendo los más vulnerables. Tal realidad implica que a nivel teórico debamos clarificar un fenómeno que subyace en la Constitución mexicana.

\section{La deconstrucción normativa del derecho a la revolución como lógica del Estado de derecho}

El debate teórico sobre la revolución remite en este punto a que, como parte de las etapas de su evolución, se dirima un conflicto principal en torno a su juridificación. Ello constituye, al mismo tiempo, un marco imprescindible para la sistematización de los diversos momentos por los que ha transitado su definición. La importancia atribuida al tema y la pluralidad de criterios existentes, no obstante, permiten la identificación de dos grupos de argumentos. En lo que a nosotros interesa, y en aras de lograr -en este punto de búsqueda y construcción teórica- el completamiento de su apreciación jurídica, se ha establecido este punto intermedio en la definición de otra cuestión de mayor peso y que más adelante se verá: la revolución como fuente de derecho. Ambos aspectos se desarrollan a partir de una cuestión común: la doctrina liberal europea sobre la revolución, estructuración que en buena medida fue posible gracias a la experiencia con que el continente sufrió las más profundas transformaciones políticas, sociales y económicas en varios momentos de su historia.

El problema que se plantea ha debido ser enfocado en su relación con la intención de la norma y la pertinencia de la revolución como acontecimiento acorde a derecho. Tal cuestión es clave en la determinación de la mejor solución, pues si logra validarse, entonces la decisión ha de tener como fundamentos criterios extrajurídicos, al margen y fuera del alcance del orden legal. Si bien esta idea adelanta nuestra postura en relación al tema, no deja de ser importante la identificación de los criterios históricos que ahora más interesa representar.

$\mathrm{Al}$ calor de los debates en torno a los contenidos de la resistencia política trascendente dentro de la Revolución francesa, Kant prejuzgó con severidad la idea de la revolución desde una perspectiva legalista, ${ }^{44}$ pese a que admiró sus más sobresalientes resultados intelectuales. Sin embargo, es un hecho que no existe uniformidad en dicho tratamiento; Gastón Jéze por ejemplo, no ofrece distinción entre revolución, golpe de Estado o insurrección que -en cualquiera

\footnotetext{
${ }^{44}$ Kant, Immanuel, La paz perpetua, Madrid, Tecnos, 1985, pp. 62-63.
} 
de sus casos sin importar la cualidad de la intención- es un hecho inválido desde la perspectiva del orden legal. ${ }^{45}$ Así también Herrfahrdt asume como análogos los elementos conformes al derecho de resistencia y al derecho a la revolución ${ }^{46}$ lo cual conlleva una sensible confusión teórica a la luz de la perspectiva liberal, lo mismo que en Cuba se advierte en Olba Benito. ${ }^{47}$

Por su parte, al definir el criterio de revolución justa, Lojendio ofrece su completa anuencia al reconocimiento del derecho de revolución como "un derecho imperativo y excepcional de la vida colectiva, destinado a rescatar la normalidad del curso de la existencia nacional, el fin natural de la agrupación política y el orden normativo de la justicia”. ${ }^{48}$ Aunque sus argumentos pudieran estar orientados a negar cualquier contradicción, es un hecho que se confunden en sus ideas los parámetros con que definir - por separado- revolución y derecho positivo de revolución, construcciones conceptuales que aunque relacionadas, son diferentes. Es decir, para Lojendio, la revolución se constituye como un derecho, y por ello asume ambos criterios como análogos.

A fines del siglo XIx, Campbell Black entendió en la revolución un derecho inherente al pueblo en su opción de echar fuera a sus gobernantes, cambiar la forma de gobierno y efectuar reformas radicales en las instituciones del Estado mediante la fuerza del levantamiento general. Ello sería posible -acorde a este criterio- siempre que los métodos constitucionales resultaran inadecuados o insuficientes para la realización de cambios, o estos se encontraran obstruidos. De tal manera, concibió el "derecho a la revolución como un derecho fundamental y natural de todo el pueblo, que no existe en virtud de la Constitución, sino a pesar de ella. Pertenece al pueblo como una inferencia necesaria de la libertad e independencia de la nación". ${ }^{49} \mathrm{Al}$ reconocer la revolución como un acontecimiento que se halla fuera de los límites de la ley, define como criterio de legitimidad moral que "únicamente las circunstancias pueden justificar el recurso extremo de la revolución",50 lo cual resulta ajustado a nuestra tesis del

\footnotetext{
${ }^{45}$ Cfr. Jéze, Gastón, Los principios generales del derecho administrativo, Madrid, Reus, 1928, p. 481.

${ }^{46}$ Véase Herrfahrdt, HeinRich, Revolución y ciencia del derecho, Madrid, Revista de Derecho Privado, 1932, p. 14.

${ }^{47}$ Véase Olba Benito, Miguel Ángel, Los derechos individuales y el régimen de facto, La Habana, Lex, 1955, pp. 83 y ss.

${ }^{48}$ Lojendio, Ignacio Maria De, El derecho de revolución, Madrid, Revista de Derecho Privado, 1941, p. 178.

${ }^{49}$ Campbell Black, Henry, Handbook of American Constitutional Law, Estados Unidos, West Publishing, 1897, p. 11. La traducción es nuestra.

${ }^{50}$ La cita sigue asi: "En general, puede decirse que este derecho existe cuando la tiranía o un gobierno corrupto o vicioso detenta el poder, del cual no puede ser despojado por medios legales, o cuando el sistema de gobierno se ha vuelto intolerable por otras causas, y los males que pueden esperarse de un levantamiento revolucionario no son tan grandes como los que hay que soportar bajo el marco del actual orden de cosas; cuando el intento es razonablemente seguro de tener éxito, y cuando el nuevo orden propuesto para ser introducido ha de ser más satisfactorio al pueblo en general que el que ha de ser desplazado." CampBell Black, Henry, Handbook of American Constitutional Law, Estados Unidos, West Publishing, 1897, p. 11. La traducción es nuestra.
} 
derecho latente de los pueblos. Ferreira, que refuerza este criterio, la concibe "como la única de las garantías de la comunidad social en autodefensa de los beneficios de la libertad". ${ }^{51}$ Linares Quintana y Ossorio y Gallardo asumen la cuestión como una forma excepcional de ultima ratio en legítima defensa asumida por los pueblos; ${ }^{52}$ Carone Dede pondera el rango de su legitimidad moral $^{53}$ e Infiesta en forma de potestad, como posibilidad en lo político, como hecho, pero no en razón de una regla jurídica autorizante. ${ }^{54}$

Es apreciable, en un ánimo más categórico, cómo Radbruch introduce el cuestionamiento de los cambios históricos que se operan en el Estado y el derecho anteponiendo el análisis de los conflictos de los fines del derecho ${ }^{55} \mathrm{y}$ la jerarquía de las ideas de valor. En ese sentido, sólo cuando estos se encuentren amenazados por un orden que no ofrezca otra alternativa, la revolución se comprenderá no sólo como una salida, sino como un derecho encaminado a rescatar la seguridad jurídica y la justicia. ${ }^{56} \mathrm{Al}$ mismo tiempo, la reflexión que ofrece Recasens Siches se halla indicada a hacer más aguda la respuesta al problema anterior. Avala, en idéntica dirección, el acontecimiento de la revolución lícita cuando se constituya en respuesta a un régimen de tiranía que se hace insoportable. ${ }^{57}$

Por su parte, Rodríguez-Arias Bustamante insta a que el derecho de revolución deba "reglamentarse detalladamente en las Constituciones nacionales como uno de los derechos naturales inalienables que corresponde a los hombres para sustituir violentamente el Gobierno que no facilite la realización del bien de la comunidad". ${ }^{58}$ Tal apreciación, de modo significativo, trasciende la cualidad deontológica del Derecho liberal, y asimismo, las facultades por este establecidas para el ejercicio positivo de la resistencia política. En este punto han manifestado su desacuerdo otros destacados autores. En los casos de Peces-Barba y Tena Ramírez, por ejemplo, reconocen en el derecho a la revolución una fundamentación estrictamente axiológica, de carácter moral,

\footnotetext{
${ }^{51}$ Ferreira, Pinto, Principios gerais do direito constitucional moderno, vol. 2, Rio de Janeiro, J. Konfino, 1955, p. 572, apud. Linares Quintana, Segundo V., Tratado de la ciencia del derecho constitucional argentino y comparado, tomo 6, Buenos Aires, Editorial Alfa, 1956., p. 297.

${ }^{52}$ Véase. Linares Quintana, Segundo V., Tratado de la ciencia del derecho constitucional argentino y comparado, tomo 6, Buenos Aires, Editorial Alfa, 1956., p. 184.

${ }^{53}$ Véase Carone Dede, Francisco, El Derecho. El Estado de Derecho. El Derecho y la Revolución. Discurso de apertura del curso académico 1953-1954, La Habana, Imprenta Universitaria, 1953, p. 54.

54 Véase INFIESTA, RAmón, El derecho de resistencia a la opresión en la Constitución cubana, La Habana, Academia Interamericana de Derecho Comparado e Internacional, 1959, p. 321.

${ }^{55} \mathrm{Cfr}$. Radbruch, Gustav, Los fines del derecho: bien común, justicia, seguridad, México, unam, 1975, pp. 57-70.

${ }^{56}$ Radbruch, Gustav, Introducción a la filosofía del derecho, México, Fondo de Cultura Económica, 1955, pp. 44-45.

${ }^{57}$ Véase Recasens Siches, Luis, Tratado general de filosofía del derecho, México, Porrúa, 1975, p. 621.

${ }^{58}$ Rodriguez-Arias Bustamante, Lino, Ciencia y filosofía del derecho. Filosofía, Derecho, Revolución, Buenos Aires, Ediciones Jurídicas Europa-América, 1961, pp. 725-726.
} 
nunca jurídica; $;^{59}$ lo contrario implicaría el reconocimiento de la posibilidad de violación del propio derecho, lo cual es desde todo punto de vista, improbable, pues se asumiría la condición de su auto negación ${ }^{60}$ y su subrogación por la violencia reconocida inadecuadamente. Con matizada anuencia a lo anterior, el criterio de Zippelius convierte en análogos los elementos de la resistencia política en todas sus manifestaciones, a los de la revolución. En ambos casos, respondiendo a la cuestión de su posible reconocimiento como derecho, le atribuye legitimidad sin legalidad $;{ }^{61}$ un sentido que se refuerza por las posturas de Willoughby ${ }^{62}$ y Duverger. ${ }^{63}$

Como puede advertirse, el problema central radica en la asignación del carácter jurídico a la revolución en el escenario positivo, esto es, en la norma; el hecho de si es posible considerar un derecho de revolución en la misma dimensión jurídica con que puede ser concebido el derecho de resistencia y, por consiguiente, en el ámbito constitucional. La sistematización de las razones consideradas esenciales alrededor de las cuales apuntan los dos principales grupos de criterios en torno al cuestionamiento sobre la revolución como fenómeno normativo obliga a una última precisión. Teniendo hasta aquí esclarecida la estructuración e integración de los elementos conformadores y por tanto conceptuales del fenómeno revolucionario, se hace menos engorroso el pronunciamiento de nuestra postura en relación al tema.

De acuerdo a la vía y función de una revolución, su esencia lleva al entendimiento de una extralimitación de la cualidad del derecho de resistencia. En tal condición, se ha venido insistiendo hasta este momento de acuerdo a los contenidos hegemónicamente asignados por la perspectiva liberal. Ello conmina a negar, desde esta lógica jurídica, que exista un derecho a la (o de) revolución positivamente otorgado, ya que sus medios obedecen a un objeto supra constitucional; es decir, la revolución no es concebible como derecho normado.

Queda entonces fuera de toda duda que el proceso revolucionario implicará, ante todo, una quiebra de la legalidad. Significa la negación del derecho establecido mediante resortes justificativos de orden moral que no son equivalentes al sentido estrictamente legal y, en consecuencia, no pueden ser convertidos

59 Véase Peces-Barba, Gregorio, Derechos fundamentales, Madrid, Editorial Latina, 1980, pp. 28-29; Tena Ramirez, Felpe, Derecho constitucional mexicano, México, Porrúa, 2009, p. 66.

60 Cfr. Carvajal Aravena, Patricio, "Derecho de resistencia, derecho a la revolución, desobediencia civil", Revista de Estudios Políticos (Nueva Época), No. 76, pp. 63-101, Madrid, Centro de Estudios Constitucionales, abril-junio de 1992, p. 96; Coronado, Mariano, Elementos de derecho constitucional mexicano, México, unam, 1977, p. 237.

${ }^{61}$ Véase Zippelus, Reinhold, Teoría general del Estado, México, unam, 1985, pp. 157-158.

${ }^{62}$ Cfr. Willoughby, Westel W. \& Rogers, Lindsay, An introduction to the problem of government, Estados Unidos, Doubleday, Page \&t Company, 1921, pp. 27-28.

${ }^{63}$ Cfr. Duverger, Maurice, Cours de Droit Constitutionnel, Paris, Librairie du Recueil Sirey, 1946, p. 135. 
en un fenómeno normativo. Acatar esto implica un desplazamiento del argumento principal al orden axiológico, en donde lo positivo se subalterna mediante un patrón que otorga legitimidad, moral en nombre de la justicia, pero no legal. Por tanto, proviene de un ejercicio que pondera la subjetividad en la canalización de la acción práctica. La revolución es un derecho latente y perpetuo en la existencia soberana de los pueblos con independencia de una norma autorizante. Sin embargo, en los marcos de la perspectiva liberal, no es posible que el derecho positivo lo justifique así. Cualesquiera que sean estas conductas, se convertirán en actos que de ninguna manera perderán el interés por parte del Estado.

\section{La revolución como fuente de derecho y el derecho de la revolución}

En el estudio jurídico de la revolución se implican también, y en última instancia, los presupuestos que sostienen la idea de su validez en el ámbito del derecho, una vez que se consagra el triunfo de la violencia revolucionaria. Ésta es una apreciación que en lo metodológico cierra el ciclo de sus análisis, de acuerdo al criterio de que es en este punto donde nace el orden jurídico que la perfecciona. Al propio tiempo, también aquí cobra sentido más estricto el principio de la revolución como forma trascendente de resistencia política. Como es nuestra intención destacar, la trascendencia viene dada por la resistencia que se desborda en el acto de creación del nuevo derecho. Vista en esta perspectiva, ocurre una transfiguración, y la revolución se constituye en un fenómeno jurídico de acuerdo a su fundamento.

Ella misma se erige en fuente, ${ }^{64}$ en forma de hechos que integran un nuevo ordenamiento capaz de brindar respuesta a los supuestos que se generan en sus circunstancias. Quiere esto decir que en el seno de la terminología jurídica que ahora sirve de base, se está en presencia de una fuente real, acepción derivada de los acontecimientos sociopolíticos y económicos que cobran vida a través de la revolución, y propician el desarrollo de sus instituciones sobre asientos de identificación, reconocimiento y consenso. Tal cuestión obedece al criterio de validez jurídica que concibe un sistema legal tras vencer la fase de la inmanente a-juridicidad que presupone su vía.

Herrfahrdt permite introducir criterios que son puntuales en la verificación de la revolución como fuente de derecho ${ }^{65}$ esto es, como proceso de creación

\footnotetext{
${ }^{64}$ Véase Garcia Maynez, Eduardo, Introducción al estudio del derecho, México, Porrúa, 1964, pp. 51 y ss.

${ }^{65}$ Véase HerRfaHRdt, Heinrich, Revolución y ciencia del Derecho, Madrid, Revista de Derecho Privado, 1932., pp. 89-92.
} 
jurídica. En ese sentido, es preciso responder: a partir de qué momento el nuevo orden jurídico está en condiciones de reclamar fuerza obligatoria; en qué forma deben ser dictadas y promulgadas las leyes del nuevo poder político; en quién residen los poderes, cómo se ejecutan las funciones; quién goza de representación ante la comunidad internacional; cómo se regulan las competencias de los nuevos órganos, y cómo coexisten con los antiguos; cómo determinar la existencia o no de responsabilidad penal y civil de las nuevas autoridades; qué relación existe entre el anterior y el nuevo orden político.

El reconocimiento del derecho de la revolución, por tanto, pasará por entender que de acuerdo a un nuevo orden, efectivamente se proporciona seguridad jurídica y validez suficiente, eficacia de acuerdo a su observancia y aplicación, y presunción de justicia derivada de los valores del progreso como elemento de origen. Estos factores, en su conjunto, dispondrán orgánicamente el carácter de legitimidad que, como es necesario entender, no puede ser reducido a los procesos ordinarios de conformación de la ley. Esta situación supone la aceptación fáctica del derecho de la revolución triunfante. ${ }^{66}$ En ello, sin embargo, no podrá desconocerse en modo alguno el criterio mayoritario de los ciudadanos de la nación, expresado a través de las reglas de convalidación y anuencia al nuevo Estado político y constitucional, fenómeno que Zippelius reconoce como consenso predominante en el orden de la justificación dentro de la comunidad jurídica. ${ }^{67}$

En esta dirección, hay un aspecto sobre el cual llamar la atención: en las circunstancias extraordinarias en que el orden triunfante puede ser capaz de concentrar todos los poderes, incluso la iniciativa constituyente, ocurre un proceso de excepcional trascendencia, en el cual la elaboración de un nuevo texto constitucional no obedecerá a un procedimiento normal y ordinario. Así, como reconoce Pérez Johnston, éste es un proceso que podrá darse de manera expresa o tácita, en virtud de que sea sometido a ratificación por parte del pueblo mediante el ejercicio de plebiscitos o asambleas de representantes, o se imponga y sea aceptado por el transcurso del tiempo. ${ }^{68}$ Ejemplos modernos de la primera opción, inspirados en el tracto iusnaturalista francés, se hallan en el 18 Brumario del año viII y el 4 de septiembre de 1871. En ambos casos se aprecia lo que Bierling describe como el reconocimiento otorgado, idea que se orienta a la convalidación jurídica del acontecimiento revolucionario. ${ }^{69}$

\footnotetext{
${ }_{66}$ Pérez Johnston, Raúl, "Notas sobre el Constituyente revolucionario, el derecho a la revolución y el derecho de la revolución", Iuris Tantum. Revista de la Facultad de Derecho, Universidad Anáhuac, año 17, No. 13, primaveraverano 2002, p. 204.

${ }^{67}$ ZippeluUs, Reinhold, Teoría general del Estado, México, unam, 1985, p. $126 .$.

${ }^{68}$ Véase Pérez Johnston, Raúl, "Notas sobre el Constituyente revolucionario, el derecho a la revolución y el derecho de la revolución", Iuris Tantum, año 17, No. 13, primavera-verano, 2002, p. 205.

${ }^{69}$ Véase BierLing, Ernst Rudolf, Juristische prinzipienlehre, Freiburg i.B. und Leipzig, 1894, pp. 40-46.
} 
Ahora bien, un gobierno instalado en el poder producto de una revolución lo será de facto en tanto no genere un nuevo orden jurídico que respalde y legalice dicho acontecimiento. Esto es, se origina un interregno en el que no será posible su reconocimiento de iure hasta tanto las condiciones determinen su convalidación. ${ }^{70}$ Ello significará la justificación en sí del derecho de la revolución, momento de consumación y perfeccionamiento mediante la forma jurídica. Se trata de la cualidad normativa de este fenómeno.

Lo anterior pasa por identificar, dentro de los contenidos que se desenvuelven en el espacio temporal inmediato y posterior a la toma del poder político, el proceso del Constituyente revolucionario, una teoría estructurada sobre la base de reconocer al derecho su capacidad de consagrar la revolución, y de forma específica, ofrecer carácter de legalidad. Ello opera de forma extraordinaria, circunstancial, y obedece al proceso en que el poder representativo del movimiento revolucionario triunfante se arroga el derecho de la representación popular y asume los contenidos y las facultades del poder constituyente. Todo esto, sin embargo, deberá validarse por mecanismos de anuencia, participación y consenso popular ${ }^{71}$ suficientes para propiciar al mismo tiempo legitimidad, seguridad jurídica y eficacia. Esta idea es esencial en la valoración positiva de la revolución hacia dentro, como fuente de derecho; y sus elementos modernos más sobresalientes se deben a las concepciones sobre la soberanía popular y del poder constituyente.

Si en ello entendemos que la Constitución es una forma de concebir y conducir una sociedad, desde una perspectiva normativa y multifacética, dinámica, ajustable y jerárquicamente preponderante, es claro deducir que el fenómeno revolucionario tenga obligatoriamente que plantearse un desacuerdo justificado y medular que por vías violentas, produzca la conquista de un poder suficiente para transformarla. Dicha transformación, que tenderá a ser positiva en nombre del progreso, producirá un ordenamiento con una nueva Constitución a la cabeza, lo cual en rigor no sólo avala su objeto, sino que es expresión formal de validez por medio de su presupuesto normativo, obligatorio y coercitivo. ${ }^{72}$

Es conveniente en este punto hallar el sentido de la prescripción interpretativa de Kelsen sobre la revolución triunfante y su relación con los ámbitos del derecho nacional e internacional. Visto así, la legitimidad del nuevo poder estará supeditada a los grados de independencia y respeto a las normas que sea capaz de desarrollar. Tales criterios son trascendentes en la determinación del

\footnotetext{
${ }^{70}$ Cfr. Willoughby, Westel W., The fundamental concepts of Public Law, New York, Macmillan, 1931, pp. 178-179; Groppalı, Alessandro, Doctrina del Estado, Milán, Dott.A. Giuffre Editor, 1952, pp. 225-226.

${ }^{71}$ Véase Tena Ramirez, Felipe, Derecho constitucional mexicano, México, Porrúa, 2009, pp. 72-74.

${ }^{72}$ Véase Kelsen, Hans, "Fundamento de la validez del derecho", La Justicia, tomo 21, No. 377, septiembre de 1961, p. 17.
} 
carácter justo del fenómeno jurídico, y además fija el valor de una legitimación indicada a la justificación misma del poder. Ese poder, entendido como dominación, es el principal elemento del Estado y debe estar avalado por el constructo interior de la legitimidad como base justificante de sí mismo, así como de la legalidad.

De acuerdo al criterio de Stammler, en procesos de esta magnitud la revolución estará sometida a "probar de un modo positivo que las medidas que se propugnan habrían de traer con bastante seguridad un progreso en sentido de la comunidad pura, dentro de las circunstancias sociales en cuestión". ${ }^{73}$ Esto también tiene que ver con el criterio con que Carré de Malberg prejuzgó un campo de actuación fuera del derecho, cuando la situación inmediata posterior al triunfo de una revolución evidencia actos que no se corresponden con los principios ni con las reglas constitucionales. ${ }^{74}$ Antes de alcanzar este punto, el movimiento precedente debió construir la base de legitimidad que en el factor popular se genera en torno a la condición moral de la violencia como vehículo de la revolución; siendo así que las determinaciones morales, en esta magnitud, trascienden al derecho.

De todo esto es preciso destacar el comportamiento de la legalidad en la revolución; esto es, la forma en que se considera ésta una fuente válida de normas jurídicas en cuya concepción se evidencia un nuevo ordenamiento. No es menos fecunda, tal como fue advertido en páginas anteriores, la idea que niega rotundamente este paradigma esencialmente normativista. Se trata, por lo general, de posiciones doctrinales más conservadoras que se dirigen a negar la posibilidad de que el derecho pueda constituirse del hecho y con menos probabilidad aún, pueda nacer derivado de lo ilícito. Aunque minoritaria en lo teórico, y más aún en la praxis, esta posición niega el valor jurídico de todo acontecimiento revolucionario. La respuesta positiva a este cuestionamiento comporta la única manera de reconocer científicamente una sistematización, y por tanto, el reconocimiento del elemento normativo en las condiciones de la revolución.

En esa dirección, y a partir del desempeño de las formas de la violencia, Santi Romano aporta a la teoría una idea indicada a justificar el carácter originario del ordenamiento jurídico en la revolución, semejante a la reflejada en la obra de Balladore Pallieri. ${ }^{75}$ Este razonamiento sirve para entender a la revolución como ordenamiento jurídico comprensible a través de su cualidad creadora intrínseca. De cualquier manera, es preciso aclarar que sólo podrá validarse

\footnotetext{
${ }_{73}$ Stammler, Rudolf, Tratado de filosofía del derecho, México, Editora Nacional, 1974, p. 432.

${ }^{74}$ Véase Carré de Malberg, Raymond, Teoría general del Estado, México, Fondo de Cultura Económica, 1998, p. 1172.

${ }^{75}$ Véase Balladore Palleri, Giogio, Dottrina dello Stato, Padova, Cedam, 1964, pp. 256 265; Balladore Palleri, Giogio, Diritto Costituzionale, Milán, Dott. A. Giuffré, 1965, p. 41.
} 
una vez coronado el éxito de un proceso revolucionario, cuyo origen no puede justificarse en el campo del derecho que pretende variarse, sino post facto, esto es, sólo después de ser superado. Lo más sobresaliente en esta interpretación es la identificación de la revolución como un fenómeno eminentemente jurídico, lo cual se explica por medio de sus grados de organización que desde una estructura embrionaria, contiene el nuevo modelo de Estado que aspira a ser instaurado tras obtener la victoria revolucionaria.

El Poder Constituyente, asumido en manos de quien detenta toda la fuerza del nuevo poder político, será el responsable de realizar la obra de legitimación legal del orden jurídico mediante la elaboración de los nuevos parámetros que prefijen el destino radicalmente nuevo de todos los elementos integrantes de la sociedad y, además, ofrezcan un sustento cierto, seguro y justo; o al menos, "relativamente justo", como reconoce Recasens Siches. ${ }^{76}$ De todas formas, en la práctica, el conjunto de estas circunstancias históricamente han implicado la validez de un proceso en donde son formuladas las leyes positivas que a manera de requisito formal dan origen a la norma de la revolución. En virtud de ello, se experimenta el fundamento de creación del nuevo derecho y, por tanto, puede identificarse su fuente, nutrida de inmediato de una cuantiosa producción legislativa y jurisprudencial que la naturaleza de las revoluciones normalmente propicia, una vez inaugurado el ciclo de su poder político. Esta es una lógica del cambio trascendente que se opera y que, en criterio de Schmill, pudiera ser interpretado como los actos normativos subsecuentes ${ }^{77}$ de los nuevos contenidos políticos, sociales y económicos que se adecuan a la nueva realidad.

Así, el derecho de la revolución alcanza el sentido que auto justifica no sólo su existencia, sino sobre todo, su validez. Tal consideración es vital en la comprensión de su efectividad y eficacia. Efectividad de acuerdo al ordenamiento jurídico como un todo, eficacia como legitimación, observancia y aplicación. En este sentido, la validez del ordenamiento jurídico en el marco de la revolución equivale a su reconocimiento como fuente de derecho, proceso que es verificable tras el triunfo; esto es, a posteriori. ¿Qué problemas jurídicos plantea esto? Que la legitimidad viene dada, en primer lugar, por el propio contexto que en forma de precedente negativo crea la necesidad revolucionaria y la construcción de un programa articulador en lo político suficientemente coherente como para ser llevado por vía de la violencia; en segundo lugar, por la capacidad de representación de un sentir notorio y nacional orientado al progreso y, finalmente, por la conquista del poder político y el proceso de instauración del nuevo derecho.

\footnotetext{
${ }^{76}$ Véase Recasens Siches, Luis, Tratado general de filosofía del derecho, México, Porrúa, 1975, p. 620.

77 Véase SchmiLl, ULISES, "El concepto jurídico de la revolución", Doxa, Cuadernos de Filosofía del Derecho, No. 30, 2007, p. 344.
} 
Se estima entonces, sobre la base del consenso y el reconocimiento, al nuevo poder político como poder jurídico, también. Tal estado evidenciará un nuevo escenario de equilibrio institucional que al mismo tiempo ofrecerá la premisa de consagración y pondrá fin al periodo revolucionario y, por tanto, a su manifestación de resistencia trascendente.

\section{Conclusiones}

El derecho de resistencia a la opresión, con sus múltiples manifestaciones y de acuerdo a su contenido esencial, se orienta al enfrentamiento legítimo del pueblo a la tiranía como expresión de gobierno contraria al bien común. Su noción adquiere una connotación troncal en el pensamiento político antiguo especialmente desde el griego, y en su evolución alcanza su juridificación a través de la figura del "derecho de resistencia”. En su desarrollo clásico, consagrado a través de los contenidos del pactum societatis, inciden los aportes de las revoluciones norteamericana y francesa, marcando con posterioridad, el siglo xx, su incorporación al tracto de los derechos fundamentales.

Tal momento convierte en dominante la perspectiva liberal positiva sobre la resistencia política. Su tratamiento se caracteriza por un pluralismo teóricometodológico expresado en diversos enfoques ideopolíticos en los que prevalece el condicionamiento al elemento legal indispensable y donde coexisten, además, contenidos axiológicos, de control del poder político, de garantía, y de salvaguarda y defensa del orden constitucional, que permiten una restringida integración conceptual.

La violencia puede constituir un fenómeno central en el ámbito de la resistencia política. Esto determina que, en su evolución histórica, se fije su ejercicio como ultima ratio, y se oriente, de acuerdo a la perspectiva liberal, por medio de su intencionalidad en dos perspectivas auto-excluibles: a la defensa y conservación del orden político y constitucional por medio del derecho de resistencia, o a su subversión-transgresión por medio de la violencia revolucionaria. El origen de ambas es la noción clásica derecho de resistencia a la opresión.

En los estudios sobre la revolución se configuran tendencias interpretativas que han sido influidas decisivamente por las experiencias históricas, hasta la adopción de una teoría moderna que ha permitido sostener que su validez ocurre, para el ámbito del derecho, una vez que se produce el triunfo de la violencia revolucionaria. Ésta, pese a presuponer un derecho esencialmente moral, latente y legítimo de los pueblos, es considerada una vía a-jurídica que constituye, junto a la idea del progreso, el factor implícito que mayor con- 
senso ofrece entre los distintos enfoques teóricos abordados. Los criterios que fundamentan a la revolución como forma trascendente de resistencia política son los siguientes: recurso de ultima ratio por vía de usos radicales de resistencia política (violencia), que ocurre como respuesta necesaria, intencional e instrumental a una crisis insuperable en la que han sido agotadas todas las formas institucional o legalmente concebidas de resistencia política (precedente negativo); un proyecto de cambio, justificado y legítimo sobre la base del consenso y la participación popular, cuyos valores armonicen la necesidad del cambio con un interés nacional; fin subversivo y transgresor del orden social y por tanto político y jurídico; modificación sui géneris de los fundamentos del Estado con un alcance totalizante: todos los ámbitos de la actividad humana (base económica, sistemas de ideas, valores, instituciones y sectores de la vida práctica) que termina por establecer un nuevo orden, y fija su fundamento jurídico por medio del derecho de la revolución.

El proceso de integración conceptual del derecho de resistencia permite un nivel argumental, en lo político y jurídico, capaz de enarbolar en el ejercicio de la resistencia política un carácter liberador, legítimo y materialmente democrático. Esto equivale a la superación del sentido conservador del derecho en el espacio liberal, y favorece el sentido clásico del republicanismo y la democracia.

Asimismo, demostrar que no hay forma de restringir jurídicamente la capacidad de un pueblo a la resistencia política, que podrá expresarse a través de la intención de salvaguardar o trascender el sistema político y jurídico del Estado, de acuerdo a su voluntad democrática.

Y por último, asegurar que el pueblo, en su condición de soberano, posea siempre la capacidad legitima y latente de encaminar la trascendencia del sistema político y jurídico del Estado opresor, con independencia de una norma autorizante.

Los pueblos en subdesarrollado están bajo constante amenaza de quiebra. En esta perspectiva, la resistencia es una actitud de cuestionamiento del poder político y el derecho, cuando los fines de éstos no revierten la alienación producida por la pobreza, el hambre, y en sentido general el resto de los flagelos que sobre nuestros pueblos aún no se erradican. El ciudadano, bajo un nuevo enfoque de empoderamiento, puede constituirse en el agente más activo para el cambio, si el derecho es capaz de adjudicarle ese valor. Un poder popular más enérgico mediante reformas constitucionales que otorgaran el derecho de resistencia como mecanismo de control del poder político y como forma de presión capaz de impulsar el compromiso de los gobiernos con el progreso.

Si bien la Constitución mexicana permite una presencia implícita de la resistencia política en el orden de la salvaguarda del sistema institucional de 
la nación, no es posible adoptar el criterio de un derecho fundamental que, en manos del ciudadano, evidencie el propósito histórico de controlar el ejercicio del poder político. En consecuencia, se establezca como un mecanismo jurídico favorable a garantizar todos los derechos, la participación y la inclusión social, la reivindicación de la justicia y el mejoramiento democrático.

\section{Bibliografía}

Aguiló, Josep, “Sobre el constitucionalismo y la resistencia constitucional”, Doxa.

Cuadernos de Filosofía del Derecho, pp. 289-317, No. 26, 2003.

Alexy, Robert, Teoría de los derechos fundamentales, Madrid, Centro de Estudios

Políticos y Constitucionales, 2008.

Arendt, Hannah, Sobre la revolución, trad. Pedro Bravo, Editorial Revista de

Occidente, S.A., Madrid, 1967.

Arendt, Hannah, "Revolución y necesidad histórica”, Revista de Occidente, pp.

301-306, Año 5, No. 48, marzo de 1967, Madrid.

Arendt, Hannah, Sobre la violencia, México, Joaquín Mortiz, 1970.

Asensi Sabater, José, Constitucionalismo y Derecho Constitucional -materiales

para una introducción-, Valencia, Tirant lo Blanch, 1996.

Balladore Palleri, Giogio, Dottrina dello Stato, Padova, Cedam, 1964.

Balladore Palleri, Giogio, Diritto Costituzionale, Milán, Dott. A. Giuffré, 1965.

Barthélemy, Joseph, Traité élémentaire de droit constitutionnel, Dalloz, París, 1926.

Bobbio, Norberto, El tiempo de los derechos, Madrid, Fundación Sistema, 1991. Burdeau, Georges, Traité de Science Politique, París, R. Pichon et R. DurandAuzias, 1968.

Campbell Black, Henry, Handbook of American Constitutional Law, Estados Unidos, West Publishing, 1897.

Carbonel, Miguel, Los derechos fundamentales en México, México, unAm - cndH, 2004.

Carone Dede, Francisco, El Derecho. El Estado de Derecho. El Derecho y la Revolución. Discurso de apertura del curso académico 1953-1954, La Habana, Imprenta Universitaria, 1953.

Carpizo, Jorge, “Constitución y revolución”, Revista de la Facultad de Derecho de México, tomo 20, No. 79-80, julio-diciembre de 1970, unAM.

Carré de Malberg, Raymond, Teoría general del Estado, 2da. Ed., trad. José Lión DePeTRE, Fondo de Cultura Económica-Facultad de Derecho UNAM, México, D.F., 1998.

Carvajal Aravena, Patricio, "Derecho de resistencia, derecho a la revolución, desobediencia civil”, Revista de Estudios Políticos, No. 76, pp. 63-101, 
Madrid, Centro de Estudios Constitucionales, abril-junio de 1992.

Carvajal Aravena, Patricio, "En la herencia de Antígona: el derecho de resistencia en J. Althusius”, Persona y Derecho. Revista de fundamentación de las instituciones jurídicas y de derechos humanos, No. 39, 1998, Facultad de Derecho, Universidad de Navarra, pp. 19-30.

Constitución del Imperio (Reich) alemán, 11 de agosto de 1919, en Textos Constitucionales españoles y extranjeros, Zaragoza, Athenaeum, 1930.

Coronado, Mariano, Elementos de derecho constitucional Mexicano, México, UNAM, 1977.

Domènech, ANToni, El eclipse de la fraternidad, una revisión republicana de la tradición socialista, Barcelona, Crítica, 2004.

Dugurt, León, Manual de Derecho Constitucional, Madrid, Librería Española y Extranjera, 1921.

Duverger, Maurice, Cours de Droit Constitutionnel, París, Librairie du Recueil Sirey, 1946.

Dworkin, Ronald, Los derechos en serio, Barcelona, Ariel, 1984.

ESMEIN, AdHÉMAR, Éléments de Droit Constitutionnel francais et comparé, París, Librairie de la Société du Recueil Sirey, 1921.

FaurÉ, Christine, Las declaraciones de los derechos del hombre de 1789, México, CNDH - Fondo de Cultura Económica, 1995.

Fayt, Carlos S., Derecho Político, tomo 2, Buenos Aires, Depalma, 1998.

Fernández de Velasco y Calvo, Recaredo, El derecho de revolución y la revolución conforme a derecho, Madrid, Imprenta Artística Española, 1914.

Finnis, John, Ley natural y derechos naturales, Buenos Aires, Abeledo-Perrot, 2000.

García Maynez, Eduardo. Introducción al estudio del derecho, México, Porrúa, 1964.

Gargarella, Roberto, El derecho a la protesta. El primer derecho, Buenos Aires, Editorial Ad-Hoc, 2007.

Gargarella, Roberto, El derecho a resistir el derecho, Buenos Aires, CIEPP-Miño y Dávila Editores, 2005.

GeAmanu, Grigore, La résistance a l'oppresion et le droti à l'insurrection, París,

Les Éditions Domat-Montchrestien, 1933.

Godwin, William, Investigaciones acerca de la justicia politica y su influencia en la virtud y la dicha generales, Buenos Aires, Americalee, 1945.

Groppali, Alessandro, Doctrina del Estado, Milán, Dott.A. Giuffre, 1952.

Gurr, Ted Robert, El porqué de las rebeliones, México, Editores Asociados, 1974. Hauriou, Maurice, Principios de Derecho Público y Constitucional, Madrid, Reus, 1929. 
Herrfahrdt, Heinrich, Revolución y ciencia del Derecho, Madrid, Revista de Derecho Privado, 1932.

Hume, DAvid, "Del contrato original", Escritos Políticos, México, Sexto piso Editorial, 2003.

Ihering, Rudolf Von, La lucha por el derecho, México, Coyoacán, 2011.

INFIESTA, RAMón, El derecho de resistencia a la opresión en la Constitución

cubana, La Habana, Academia Interamericana de Derecho Comparado e Internacional, 1959.

JefFerson, Thomas, Autobiografía y otros escritos, Madrid, Tecnos, 1987. Jellinek, George, Teoría general del Estado, Buenos Aires, Albatros, 1978. Jellinek, George, La Declaración de los derechos del Hombre y del Ciudadano.

Estudio de Historia Constitucional Moderna, México, Universidad Nacional Autónoma de México, 2000.

JÉZE, Gastón, Los principios generales del derecho administrativo, Madrid, Reus, 1928.

Kant, Immanuel, La paz perpetua, Madrid, Tecnos, 1985.

Kelsen, Hans, Teoría pura del derecho, México, unam, 1983.

Kelsen, Hans, "Fundamento de la validez del derecho", en La Justicia, tomo 21, No. 377, septiembre de 1961.

Linares Quintana, Segundo V., Tratado de la ciencia del derecho constitucional argentino y comparado, tomo 6, Buenos Aires, Editorial Alfa, 1956.

Lucas Verdú, Pablo y Murillo de la Cueva, Pablo Lucas, Manual de derecho político, vol. 1, Madrid, Tecnos, 2000.

Lojendio, Ignacio María De, El derecho de revolución, Madrid, Revista de Derecho Privado, 1941.

Montesquieu, Charles de, Del espiritu de las leyes, Madrid, Tecnos, 1985.

Moore, Barrington, La injusticia: bases sociales de la obediencia y la rebelión,

México, unAM, 2007.

Olba Bentto, Miguel Ángel, Los derechos individuales y el régimen de facto, La Habana, Lex, 1955.

Ossorio y Gallardo, Ángel, Los derechos del hombre, del ciudadano y del Estado, Serie Biblioteca del Autodidacto No. 2, Editorial Claridad, S.A., Buenos Aires, 1946.

Peces-Barba Martínez, Gregorio, Derechos fundamentales, Madrid, Editorial Latina, 1980.

Peces-Barba Martínez, Gregorio, La Constitución y los derechos, Colombia, Universidad Externado de Colombia, 2006.

Peirano Facio, Jorge, El derecho de resistencia, Uruguay, Talleres Gráficos 33, 1945. 
PÉRez Johnston, Raúl, "Notas sobre el Constituyente revolucionario, el derecho a la revolución y el derecho de la revolución”, Iuris Tantum, año 17, No. 13, primavera-verano, 2002.

Pérez LuÑo, Antonio, Los derechos fundamentales, Madrid, Tecnos, 1988, p. 21. Pérez Royo, Javier, Curso de Derecho Constitucional, Madrid, Marcial Pons, 1997. Peyrano, Alberto, Derecho de resistencia, Buenos Aires, Imprenta de M. Viedma, 1945.

Pichardo, Hortensia, "Constitución de la República de Cuba, Convención Constituyente de 1940", Documentos para la Historia de Cuba, tomo 4, La Habana, Editorial de Ciencias Sociales, 1980, p. 338.

Prieto Valdés, Martha, "La defensa de los derechos: una necesidad en cualquier momento”, en Ana María Álvarez-Tabío Albo y Andry Matilla Correa (coord.), El derecho público en Cuba a comienzos del siglo XXI. Homenaje al doctor Fernando Álvarez Tabio, La Habana, uH, 2011.

Quintero, CÉSAR, "El principio de la separación de poderes y su valor actual en Iberoamérica”, en Memoria del III Congreso Iberoamericano de Derecho Constitucional, tomo 2, México, unAm, 1987, pp. 749-784.

Rawls, John, Teoría de la justicia, México, Fondo de Cultura Económica, 1979. Recasens Siches, Luis, Tratado general de filosofía del derecho, México, Porrúa, 1975.

Rodríguez-Arias Bustamante, Lino, Ciencia y filosofía del derecho. Filosofía, Derecho, Revolución, Buenos Aires, Ediciones Jurídicas Europa-América, 1961. Rodríguez Varela, Jorge R y Vanossi, Alberto, "El derecho de resistencia” (Separata de Anticipo de Anales, Academia Nacional de Derecho y Ciencias Sociales, No. 34, Año XLI, segunda época, 1997, Buenos Aires).

Rousseau, Jean-Jacques, El contrato social, Buenos Aires, Tor, 1940.

SAmpay, Arturo EnriQue, El derecho de resistencia. Su inadmisibilidad en la Constitución del Estado de Derecho, Buenos Aires, La Facultad, 1938.

Schmill, Ulises, "El concepto jurídico de la revolución", Doxa, Cuadernos de filosofía del derecho, pp. 335-354, No. 30, 2007.

Schmitt, CARL, La defensa de la Constitución. Estudio acerca de las diversas especies y posibilidades de salvaguardia de la Constitución, trad. Manuel SÁnchez Sarto, Tecnos, Madrid, 1983.

Schmitt, CARL, La dictadura desde los comienzos del pensamiento moderno de la soberania hasta la lucha de clases proletaria, Madrid, Alianza, 2003.

Schmitt, EBERHARD, Introducción a la historia de la Revolución francesa, Madrid, Cátedra, 1985.

SieyÉs, Emmanuel José, Escritos políticos, México, Fondo de Cultura Económica, 1993. 
Soler, Sebastián, Ley, historia y libertad, Col. Biblioteca del Instituto Argentino de Filosofía Jurídica y Social, Editorial Losada, S.A., Buenos Aires, 1943.

Stammler, Rudolf, Tratado de filosofía del derecho, México, Editora Nacional, 1974.

Tena Ramírez, Felipe, Derecho constitucional mexicano, México, Porrúa, 2009.

TARr, G. Alan, Comprendiendo las constituciones estatales, México, unAM, 2009.

Ugartemendia Eceizabarrena, Juan Ignacio, "El derecho de resistencia y su constitucionalización”, Revista de Estudios Políticos, No. 103.

Vanossi, Jorge R., Teoría Constitucional, tomo 1, Buenos Aires, Depalma, 1975.

Vitale, Ermanno, "Cambio político, Constitución y derecho de resistencia”, Isonomía, No. 32, México, ITAM, abril de 2010.

Willoughby, Westel W., The fundamental concepts of Public Law, New York, Macmillan, 1931.

Willoughby, Westel W. and Lindsay Rogers, An introduction to the problem of government, Estados Unidos, Doubleday, Page \&t Company, 1921.

Zippelius, Reinhold, Teoría general del Estado, México, unam, 1985. 